Article

\title{
Facile Synthesis of Nitrogen-Doped Carbon Dots from Lignocellulosic Waste
}

\author{
Mohammed Abdullah Issa ${ }^{1}\left(\mathbb{D}\right.$, Zurina Z. Abidin 1,*(D), Shafreeza Sobri ${ }^{1}$, Suraya Rashid ${ }^{1}$, \\ Mohd Adzir Mahdi ${ }^{2}$, Nor Azowa Ibrahim ${ }^{3}$ and Musa Y. Pudza ${ }^{1}$ (I) \\ 1 Department of Chemical and Environmental Engineering, Faculty of Engineering, Universiti Putra Malaysia, \\ 43400 UPM Serdang, Malaysia; mohbaghdadi1@yahoo.com (M.A.I.); shafreeza@upm.edu.my (S.S.); \\ suraya_ar@upm.edu.my (S.R.); pudzamusa@gmail.com (M.Y.P.) \\ 2 Department of Computer \& Communications Systems Engineering, Faculty of Engineering, \\ Universiti Putra Malaysia, 43400 UPM Serdang, Malaysia; mam@upm.edu.my \\ 3 Department of Chemistry, Faculty of Science, Universiti Putra Malaysia, 43400 Serdang, Malaysia; \\ norazwa@upm.edu.my \\ * Correspondence: zurina@upm.edu.my
}

Received: 12 September 2019; Accepted: 26 September 2019; Published: 22 October 2019

\begin{abstract}
The current research mainly focuses on transforming low-quality waste into value-added nanomaterials and investigating various ways of utilising them. The hydrothermal preparation of highly fluorescent $\mathrm{N}$-doped carbon dots $(\mathrm{N}-\mathrm{CDs}$ ) was obtained from the carboxymethylcellulose (CMC) of oil palm empty fruit bunches and linear-structured polyethyleneimines (LPEI). Transmission electron microscopy (TEM) analysis showed that the obtained N-CDs had an average size of $3.4 \mathrm{~nm}$. The $\mathrm{N}-\mathrm{CD}$ s were monodispersed in aqueous solution and were strongly fluorescent under the irradiation of ultra-violet light. A detailed description of the morphology and shape was established using Fourier transform infrared (FTIR) spectroscopy and X-ray photoelectron spectroscopy (XPS). It was shown that LPEI were successfully tuned the fluorescence (PL) properties of CDs in both the intrinsic and surface electronic structures, and enhanced the quantum yield (QY) up to $44 \%$. The obtained N-CDs exhibited remarkable PL stability, long lifetime and $\mathrm{pH}$-dependence behaviour, with the excitation/emission maxima of 350/465.5 nm. Impressively, PL enhancement and blue-shifted emission could be seen with the dilution of the original N-CDs solution. The obtained N-CDs were further applied as fluorescent probe for the identification of $\mathrm{Cu}^{2+}$ in aqueous media. The mechanism could be attributed to the particularly high thermodynamic affinity of $\mathrm{Cu}^{2+}$ for the $\mathrm{N}$-chelate groups over the surface of $\mathrm{N}-\mathrm{CD}$ s and the fast metal-to-ligand binding kinetics. The linear relationship between the relative quenching rate and the concentration of $\mathrm{Cu}^{2+}$ were applied between 1-30 $\mu \mathrm{M}$, with a detection limit of $0.93 \mu \mathrm{M}$. The fluorescent probe was successfully applied for the detection of $\mathrm{Cu}^{2+}$ in real water. Moreover, a solid-state film of N-CDs was prepared in the presence of poly (vinyl alcohol) (PVA) polymer and found to be stable even after 72-h of continuous irradiation to UV-lamp. In contrast to the aqueous $\mathrm{N}-\mathrm{CDs}$, the composite film showed only an excitation independent property, with enhanced PL QY of around 47\%. Due to the strong and stable emission nature of N-CDs in both aqueous and solid conditions, the obtained $\mathrm{N}-\mathrm{CDs}$ are ideal for reducing the overall preparation costs and applying them for various biological and environmental applications in the future.
\end{abstract}

Keywords: carbon dots; $\mathrm{N}$-doped carbon dots; fluorescent probe; $\mathrm{Cu}^{2+}$ sensor; composite film

\section{Introduction}

Carbon dots (CDs), a new member of the fluorescent carbon nanostructures family, with sizes of less than $10 \mathrm{~nm}$, have drawn considerable attention among researchers since their first fundamental 
report [1]. CDs consist of a graphitic or amorphous carbon core coated with oxygen-functionalities, polymers and other active groups with respect to synthesis condition and surface chemistry [2]. In contrast to organic dyes and traditional semiconductor quantum dots, CDs possess remarkable properties, including tuneable photoluminescence, chemical inertness, efficient production and good biocompatibility [3-5]. Due to these beneficial characteristics, they are useful in the areas of chemical sensing, bio-imaging, photocatalysis, and wastewater treatment [6,7].

Many methods, including the arc-discharge approach [8], electrochemical oxidation [9], microwave treatment [10] and hydrothermal route [11], with a large diversity of carbonaceous precursors, have been recently established for the production of CDs. As summarized in Table S1, the usage of carbon-based bulk materials, such as candle soot [12], activated carbon [13] and graphitic rods [14] resulted in low quantum yield (QY). Thus, a broad range of CDs have been synthesized using small molecules that serve as single precursors [15-17]. However, CDs synthesized from sole small molecules show weaker fluorescence (PL) compared to those from dual small precursors. Dual precursors, including the usage of cellulose/urea [18], glucose/polyethyleneimine (PEI) [19] and microcrystalline cellulose/ethylenediamine (EDA) [20] were used for the production of N-CDs, in which one serving as the carbon source, the other as nitrogen source or passivation agent. An N-doping source, also known as an electron donator, has been shown to be the most convenient element on the stimulating of electronic states of the carbonaceous material by introducing new energy states corresponding to the $\mathrm{N}$-dopants [5]. In spite of their promising optical properties and low-toxic behaviour, several drawbacks limit their analytical applications, such as long duration synthesis processes from 7-72 $\mathrm{h}$ [16,19-30], low quantum yield of using sole precursors [10,14,19,23,24,27,29-47], or efficient quantum yield along with long duration synthesis process even after doping CDs with various heteroatoms $[16,20-22,25,26]$. Since the obtained QY is highly dependent on the particle size, choice of dopant, influence of the passivating species, $\mathrm{pH}$, time, temperature, nature of the solvent, several shortcomings such as $\mathrm{PL}$ origin and the corresponding interaction variables in production are still controversial and need to be further discussed. Moreover, the ease of the processing and no need for high temperature and long duration synthesis processes is of great interest.

Water pollution by metal ions released by anthropogenic activities has become a worldwide issue owing to their severe threats to human health and environment $[48,49]$. One should note that $\mathrm{Cu}^{2+}$ is necessary in significant physiological functions. Nevertheless, excessive doses of $\mathrm{Cu}^{2+}$ in the human body can induce an acknowledged risk of diseases, including Menkes, Prion, Wilsons and Alzheimer's, and so on [50]. Moreover, copper is highly exploited by industries, environment, and domestic functions. Therefore, it would be sensible to develop highly fluorescent $\mathrm{N}-\mathrm{CDs}$ in a significantly short synthesis time as well as to improve the sensitive detection of copper ions in aqueous media.

In the present work, we demonstrated the use of low-cost wastes of carboxymethylcellulose (CMC) as the carbon material for the production of fluorescent CDs since various physical characteristics of CMC resulted in different degrees of polymerization. Linear-structured polyethyleneimine (LPEI) was selected as the $\mathrm{N}$-doping source/surface passivation agent in an attempt to enhance the PL emission of CDs. LPEI polymer has been widely used for various fields such as solar cells, light emitting diodes, transistors owing to its polycationic character, which can provide CDs with amine groups with the ability to recognize analytes. The PL QY has been optimized by studying the effects of reaction temperature, time and LPEI dosage on the optical characteristics of N-CDs. The optimized N-CDs were thoroughly characterized using various analytical techniques, and their fluorescence stability in terms of LPEI-CDs concentration, $\mathrm{pH}$ effect, illumination time, ionic strength, surface charge and storage time was studied. The as-prepared N-CDs with bright greenish emission have shown a fluorescence QY of $44 \%$ which was found to be six times higher than the undoped CDs. The N-CDs exhibited both excitation dependence/independence emission and excellent stability for more than six months without any precipitation. Moreover, both PL emission enhancement and blue-shifted of emission maxima were observed with a decreasing concentration of $\mathrm{N}-\mathrm{CD}$. The fluorescent probe was successfully 
applied for the determination of $\mathrm{Cu}^{2+}$ in aqueous solution, and a possible quenching mechanism was thoroughly studied. Fluorescent composite film was also prepared by the incorporating N-CDs into poly (vinyl alcohol) (PVA). Compared to the N-CDs solution, the solid film displayed higher QY (47\%) with only an excitation-independent wavelength feature.

\section{Materials and Methods}

\subsection{Reagents}

CMCs were purchased from Waris Nove Company, Balok, Malaysia. The analytical-grade of LPEI ( $\mathrm{Mn} ~ 5000)$ and quinine sulphate were obtained from Sigma-Aldrich (St. Louis, MO, USA). $\mathrm{MgSO}_{4}$, $\mathrm{MnSO}_{4}, \mathrm{ZnSO}_{4}, \mathrm{CaCl}_{2}, \mathrm{CdCl}_{2}, \mathrm{HgCl}_{2}, \mathrm{FeCl}_{3}, \mathrm{FeCl}_{2}, \mathrm{PbNO}_{3}, \mathrm{NaOH}, \mathrm{HCl}, \mathrm{NaCl}, \mathrm{AlCl}_{3}, \mathrm{KCl}, \mathrm{BaCl}$, LiCl, $\mathrm{AgNO}_{3}, \mathrm{CoCl}_{2}, \mathrm{NiCl}_{2}, \mathrm{CuNO}_{3}$ and PVA were purchased from $\mathrm{R}$ and $\mathrm{M}$ marketing, Selangor, Malaysia. Throughout the preparation of the solution, deionised water (DI) with a resistivity of $18.25 \mathrm{M} \Omega \mathrm{cm}$ was used.

\subsection{Preparation of $\mathrm{N}-\mathrm{CD}$ s}

Fine carboxymethylcellulose, $0.1 \mathrm{~g}$, and a suitable amount of LPEI were added into $25 \mathrm{~mL}$ of DI water. Ultrasonication was the method used in this stage so the LPEI was added uniformly. Once they were mixed together, they were added into a $50 \mathrm{~mL}$ Teflon-lined stainless-steel reactor. The mixture was then sealed and heated at $260{ }^{\circ} \mathrm{C}$ for $2 \mathrm{~h}$ in an oven. The solution was cooled down at room temperature and then centrifuged at $10,000 \mathrm{rpm}$ for $12 \mathrm{~min}$ so that a free-dark carbonaceous material could be obtained. The final solution was purified through vacuum filtration $(0.22 \mu \mathrm{m})$ to remove the precipitate. It was then placed into a dialysis membrane $(1 \mathrm{kDa})$ so that the contents of salt ions were eliminated. Similar procedures, except the addition of LPEI, were conducted for the preparation of the undoped carbon dots as a blank solution sample.

\subsection{Instrumentation}

Transmission electron microscopy (TEM) and high-resolution TEM (HRTEM) readings were carried out using A Tecnai G2 F20 electron microscope, with an acceleration voltage of $200 \mathrm{kV}$. The Fourier transform infrared (FTIR) (Thermo Nicolet FTIR spectrometer of $4 \mathrm{~cm}^{-1}$ resolution) was measured with $\mathrm{KBr}$ as a standard within the range from 650 to $4000 \mathrm{~cm}^{-1}$. UV-vis spectra were recorded with a spectral range of 200-800 nm using Shimadzu UV-1800 Spectrophotometer (Shimadzu Corporation, Tokyo, Japan). PL studies were measured in quartz cuvettes with $1 \mathrm{~cm}$ path length using LS 55 Fluorescence Spectrometer (PerkinElmer, Waltham, MA, USA) with a slit width of 15 and $5 \mathrm{~nm}$ for excitation and emission, respectively and a scan rate of $240 \mathrm{~nm} / \mathrm{min}$. X-ray photoelectron spectra (XPS) (Physical Electronics PHI 5400 spectrometer, Mimos Semiconductors, Kuala Lumpur, Malaysia) were measured using Al-Ka radiation ( $h v=1486.6 \mathrm{eV})$. Prior to de-convolution, charge correction was established at $\mathrm{C}_{1 \mathrm{~s}}$ by setting binding energies of $\mathrm{C}-\mathrm{C}$ and $\mathrm{C}-\mathrm{H}$ at $284.8 \mathrm{eV}$. The $\mathrm{pH}$ values were obtained by a PB-10 pH-meter (Beijing Sartorius Instruments Co. Ltd., Beijing, China) and zeta potential study of N-CDs was carried out using Zetasizer Nano ZS (Malvern, UK). Origin 9.0 (OriginLab Corporation, Northampton, MA, USA) was used for PL curve fitting and Design-Expert 10.0 (stat Ease Inc., Minneapolis, MN, USA) was carried out for statistical analysis. The fluorescence QY was calculated based on the comparative method [51-53] using the following equation:

$$
\mathrm{QY}=\mathrm{Q}_{\mathrm{R}} \frac{I}{I_{R}} \frac{O D_{R}}{O D} \frac{\eta^{2}}{\eta_{R^{2}}},
$$

where $(I)$ is integrated intensity, $(O D)$ is optical density and $(\eta)$ is the refractive index. Quinine sulphate in $0.1 \mathrm{M} \mathrm{H}_{2} \mathrm{SO}_{4}(\mathrm{QY}=54 \%$ ) was used as a fluorophore reference. 


\subsection{Procedures for $\mathrm{Cu}^{2+}$ Sensing}

In a typical assay, the fluorescent probe was prepared as follow: $75 \mu \mathrm{M}$ of the as-made $\mathrm{N}-\mathrm{CDs}$ were taken in a $50 \mathrm{~mL}$ measuring flask, filled up to the mark using DI, mixed completely and used throughout all the detection experiments. The sensitivity of the $\mathrm{N}-\mathrm{CD}$-based sensor towards $\mathrm{Cu}^{2+}$ ions was performed by adding $2 \mathrm{~mL}$ of probe into $2 \mathrm{~mL}$ of different concentrations of $\mathrm{Cu}^{2+}$. After incubation for $1 \mathrm{~min}$ at room temperature, the PL spectra were recorded with excitation/emission peaks at $350 / 465.5 \mathrm{~nm}$. The selectivity study was assessed by adding $50 \mu \mathrm{M}$ of metal cations, including Fe (III), $\mathrm{Mg}$ (II), $\mathrm{Fe}$ (II), Pb (II), Ca (II), Cu (II), Ni (II), Cd (II), Hg (II), Zn (II), Ag (I), Co (II), Li (I), Ba (II), K (I), $\mathrm{Al}$ (III) and $\mathrm{Mn}$ (II) ions into the probe using the aforementioned procedure.

\subsection{Analysis of Real Samples}

The water sample was acquired from the tap of biochemical lab (UPM, Selangor, Malaysia). Prior to the detection, the sample was filtered using a $0.22 \mu \mathrm{M}$ filter membrane. The samples were then spiked with different concentrations $(15,30,60 \mu \mathrm{M})$ of the copper solution and analysed using the developed sensing system. The precision of the analysis technique was evaluated based on the relative standard deviations (RSD) using three replicate measurements according to the following formula:

$$
\text { Recovery }(\%)=S_{\text {Spiked }} \times R_{\text {Real }} / S_{\text {Spiked }} \times 100 \% \text {, }
$$

where $S_{\text {Spiked }}=$ calculated $\mathrm{Cu}$ (II) in spiked sample $(\mu \mathrm{M})$ and $\mathrm{R}_{\text {Real }}=\mathrm{Cu}$ (II) in the real sample solution $(\mu \mathrm{M})$.

\subsection{Immobilization of PVA/N-CDs Composite Film}

The preparation of the PVA solution was done by having $1 \mathrm{~g}$ of PVA powder dissolved into $10 \mathrm{~mL}$ of DI water. Specifically, the mixture was heated at $90^{\circ} \mathrm{C}$ and constantly stirred for $2 \mathrm{~h}$ until the powder was completely dissolved. After that, $1 \mathrm{~mL}$ of $1 \mathrm{mg} \mathrm{mL}^{-1} \mathrm{~N}-\mathrm{CDs}$ was mixed with $1 \mathrm{~mL}$ of PVA solution and stirred continuously. Once the homogenous gel mixture was formed, it was poured into a clean glass substrate. The heating process for this mixture was heated in an oven at $80^{\circ} \mathrm{C}$ for $1 \mathrm{~h}$. Finally, the PVA/N-CDs composite film was peeled off from the glass slide surface so that a freestanding film could be obtained.

\section{Results and Discussion}

\subsection{Synthesis of $\mathrm{N}-\mathrm{CDs}$}

The fluorescent $\mathrm{N}-\mathrm{CD}$ s were prepared from CMC of oil palm empty fruit bunch with the incorporation of LPEI using a facile hydrothermal carbonisation (HTC) route. The synthesis preparation of the N-CDs is illustrated in Scheme 1. EFB cellulose mainly comprised of D-glucose subunits, which were linked to each other by $\beta-(1,4)$-glycosidic bonds. The abundance of hydroxyl and ether groups within the CMC structure could provide the elemental and structural basis for the formation of CDs [53]. Since CMC does not contain $\mathrm{N}$-functionalities in its framework, obtaining superior PL properties of these renewable bioresources is the critical step. The abundant primary and secondary amino groups in the backbone basis of LPEI polymer could play three basic roles, which are (i) a surface passivation species; (ii) a $\mathrm{N}$ incorporation for obtaining $\mathrm{N}-\mathrm{CDs}$; and (iii) cupric amine formation to increase the coordination interaction of $\mathrm{N}-\mathrm{CD}$ s with metal ions.

To obtain the optimal fluorescent efficiency of $\mathrm{N}-\mathrm{CDs}$, several variables, including synthesis temperature, reaction time, and dosage of LPEI were optimized, as seen in Tables S2 and S3. Under optimal conditions, N-CDs with QY of up to $44 \%$ were obtained. The negative effect of $\mathrm{N}$ dosage on QY (Table S2) could be related to the wrapping effect of $\mathrm{N}-\mathrm{CD}$ s with excessive amino groups, leading to the reduction of surface defects and result in lower QY [18,54]. Moreover, two hours of synthesis duration was found to be sufficient for efficient carbonisation conversion rate and obtaining highest 
QY, in which a further increase in time could result in the decomposition of reactive functional species during the HTC process (Table S3). However, it is believed that only a polymerization reaction might have occurred as a result of the short reaction time. It is worth mentioning that short synthesis time of the present study was sufficient for obtaining higher QY of N-CDs compared to CDs synthesized via HTC treatment of different natural and waste materials (Table S1).

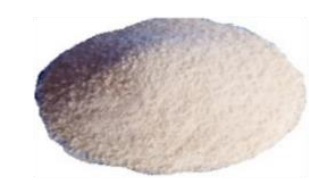

Carboxymethylcellulose

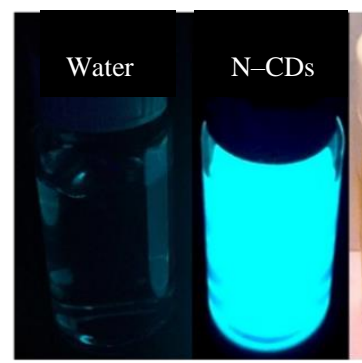

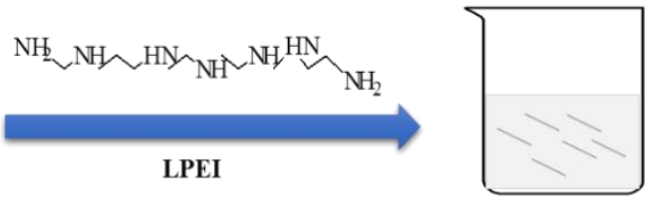

Ultrasonication

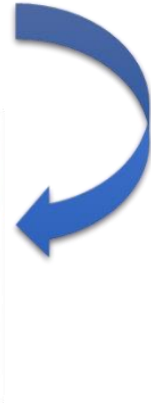

Scheme 1. Schematic representation of the preparation of fluorescent N-doped carbon dots (N-CDs) from carboxymethylcellulose (CMC) and linear-structured polyethyleneimines (LPEI).

\subsection{Surface Morphology and Structural Analysis of N-CDs}

The surface morphology of N-CDs was characterised by TEM and HRTEM. As shown in Figure $1 \mathrm{a}, \mathrm{b}, \mathrm{N}-\mathrm{CDs}$ were homogeneous, with quasi-spherical and monodispersed particles. According to the particle size distribution histogram, which was calculated from one hundred particles (Figure 1d), the N-CDs had a size distribution ranging from 3 to $8 \mathrm{~nm}$ with an average size of around $3.4 \pm 1$ $\mathrm{nm}$. The HRTEM image (Figure 1c) revealed that most particles exhibited a clear crystalline structure with an interplanar distance of $0.25 \mathrm{~nm}$. This distance was near to the value for the [002] planes of a graphitic-like structure. The crystallinity lattice framework of the N-CDs, which was observed in the HRTEM images suggested that these nanodots had the inner core of graphite. This finding was in agreement with those reported in previous studies [55-57].

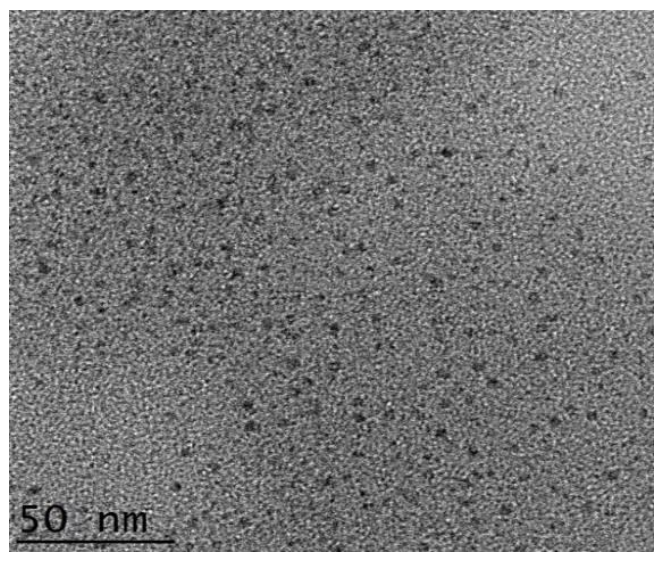

(a)

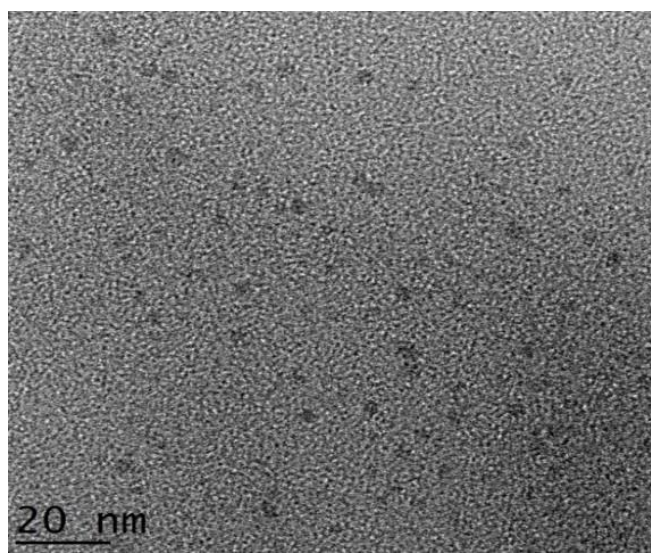

(b)

Figure 1. Cont. 


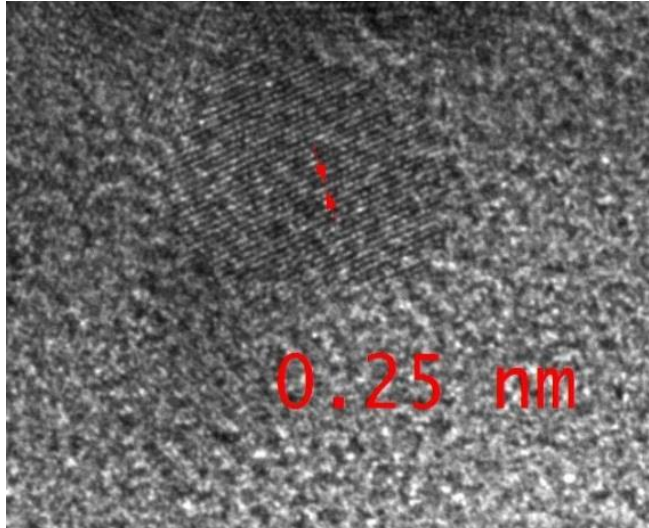

(c)

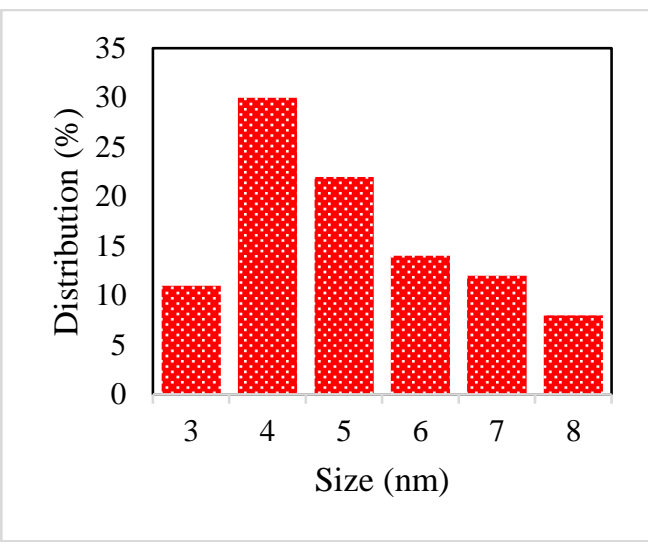

(d)

Figure 1. TEM images of the N-CDs in different magnifications (a,b), high-resolution (HR)TEM image (c) and the histogram showing the distribution particle size (d).

The FTIR spectrum shown in Figure 2a presents typical absorptions of undoped and N-CD aqueous solutions. It could be seen from the graph that there was a sharing absorption peak at $3381.43 \mathrm{~cm}^{-1}$, which corresponded to the $\mathrm{O}-\mathrm{H}$ stretching vibration. Meanwhile, the peaks at $2124.54 \mathrm{~cm}^{-1}$ and $725.11 \mathrm{~cm}^{-1}$ assigned to $\mathrm{C}-\mathrm{H}$ stretching and bending vibrations, respectively [20,58,59]. In comparison to the $\mathrm{C}-\mathrm{H}$ bending vibrations of $\mathrm{N}-\mathrm{CDs}$, the peak of undoped $\mathrm{CDs}$ was wider. The existence of these hydrophobic species could be correlated with the PL loss due to decreased carrier mobility in the polar environment [60]. The stretching vibration centred at $1641.26 \mathrm{~cm}^{-1}$ might have been attributed to $\mathrm{C}=\mathrm{O}$ groups, suggesting the formation of carboxylic acid groups [29]. Moreover, the bands at 1373.44, 1218.04 and $1093.77 \mathrm{~cm}^{-1}$ corresponded to the saccharide structure [56].

The presence of LPEI in the carbon framework of N-CDs could lead to significant changes compared to the undoped CDs. More specifically, the peak of C-N at $1266 \mathrm{~cm}^{-1}$ was formed after LPEI addition. This peak could have resulted from the destruction of the CMC saccharide structure and loss of characteristic vibrations via dehydration and passivation process $[54,56]$. Meanwhile, the bending vibration of $\mathrm{C}-\mathrm{O}$ and $\mathrm{C}-\mathrm{O}-\mathrm{C}$ appeared at wavenumber of 1045.87 and $1016.57 \mathrm{~cm}^{-1}$, respectively, indicating that oxidized species were present $[7,29]$. The above investigations confirmed that hydroxyl, carboxyl, carbonyl and amino containing groups were formed through the HTC of CMC and LPEI, which imparted hydrophilicity and stability to $\mathrm{N}-\mathrm{CDs}$ via creating the energy gaps [5].

To investigate the surface chemical composition of N-CDs, both the undoped and N-CDs were characterized using Energy-dispersive X-ray spectroscopy (EDS) as presented in Table S4. In comparison to undoped CDs, the carbon content of $\mathrm{N}-\mathrm{CD}$ s was greatly increased from $\sim 54.3 \%$ to $\sim 64.6 \%$ along with the decrease in the contents of oxygen. This indicated the high level of aromatization with the elimination of oxygen functional groups. Additionally, the presence of nitrogen contents with atomic ratio of $\sim 19.4 \%$ after doping CDs with LPEI confirmed the successful synthesis and embedment of amino species into the final surface structure of N-CDs [61].

XPS spectra was applied to verify the surface composition of the N-CDs. As shown in Figure 2b, the as-synthesized N-CDs exhibited three peaks, which mainly corresponded to carbon, nitrogen and oxygen (C: $64.61 \mathrm{wt} \%, \mathrm{~N}: 19.38 \mathrm{wt} \%, \mathrm{O}: 11.23 \mathrm{wt} \%$ ). The nitrogen weight content of the present $\mathrm{N}-\mathrm{CDs}$ is much higher than the $\mathrm{N}-\mathrm{CD}$ s obtained from nitrogen-doped CDs using different natural carbon sources such as peach gum (14.1\%) [62], Actinidia deliciosa (6.9\%) [61] and grass (4.23\%) [54]. The spectrum of the $\mathrm{C}_{1 \mathrm{~s}}$ region (Figure 2c) was deconvoluted into four single peaks attributed to various $\mathrm{C}$ states. The dominant peak at $284.59 \mathrm{eV}$ was ascribed to $\mathrm{sp}^{3}$-hybridized $(\mathrm{C}-\mathrm{C})$ carbon, while the other peaks at $285.53,287.35$ and $287.97 \mathrm{eV}$ corresponded to $\mathrm{C}-\mathrm{N}, \mathrm{C}-\mathrm{O}$ and $\mathrm{C}=\mathrm{O}$ bonds, respectively. Based on the $\mathrm{N}_{1 \mathrm{~s}}$ spectrum shown in Figure $2 \mathrm{~d}$, three peaks of graphitic $\mathrm{N}-(\mathrm{C})_{3}$, pyridinic $\mathrm{N}$ and $\mathrm{N}-\mathrm{H}$ were observed at 398.8, 399.7 and $400.75 \mathrm{eV}$, respectively. This observation gave evidence that nitrogen had been effectively doped into the $\mathrm{sp}^{2}$-conjugated domains of $\mathrm{N}-\mathrm{CDs}$ in different modes $[18,20]$, 
which was consistent with FTIR measurement results. The $\mathrm{O}_{1 \mathrm{~s}}$ spectrum shown in Figure 2e confirmed the existence of two characteristic oxygen states of $\mathrm{O}-\mathrm{H}$ and $\mathrm{C}=\mathrm{O}$ at 530.73 and $531.93 \mathrm{eV}$, respectively. The XPS data suggested that the obtained N-CDs were greatly functionalized by different polar oxygen/nitrogen groups. These findings were in agreement with the results obtained from FTIR and EDS analysis.

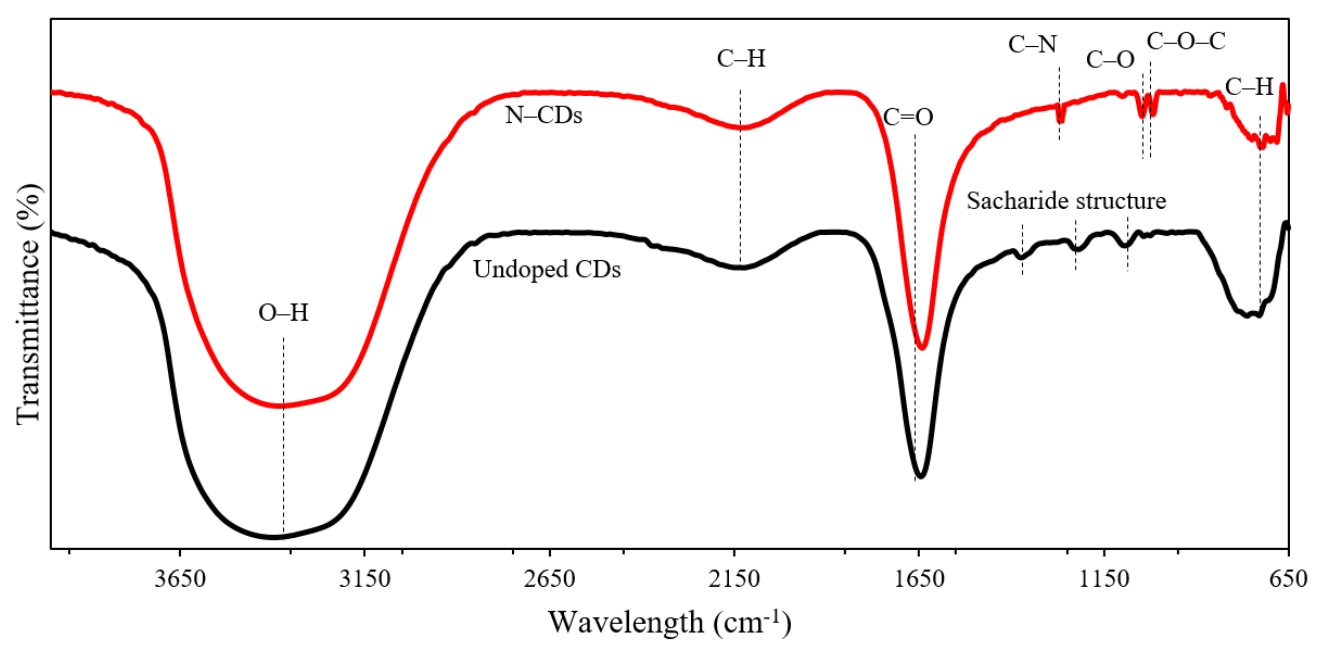

(a)

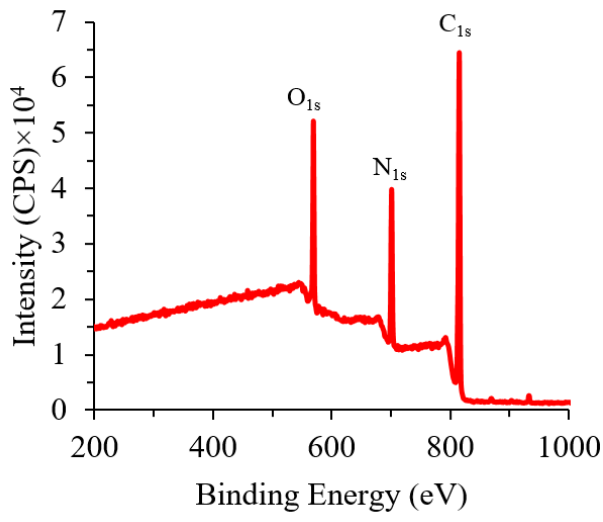

(b)

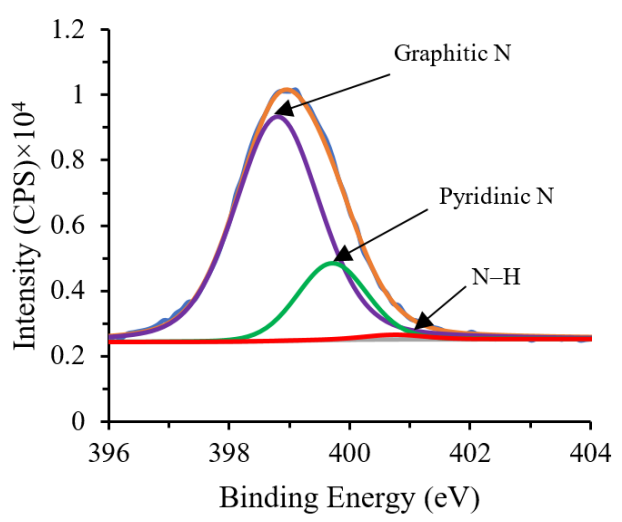

(d)

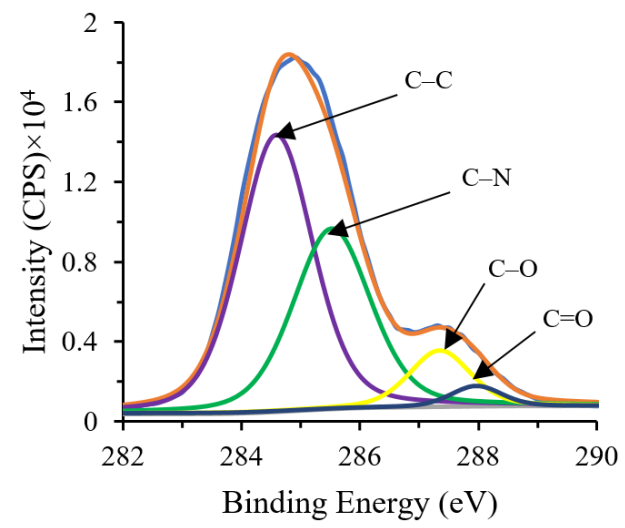

(c)

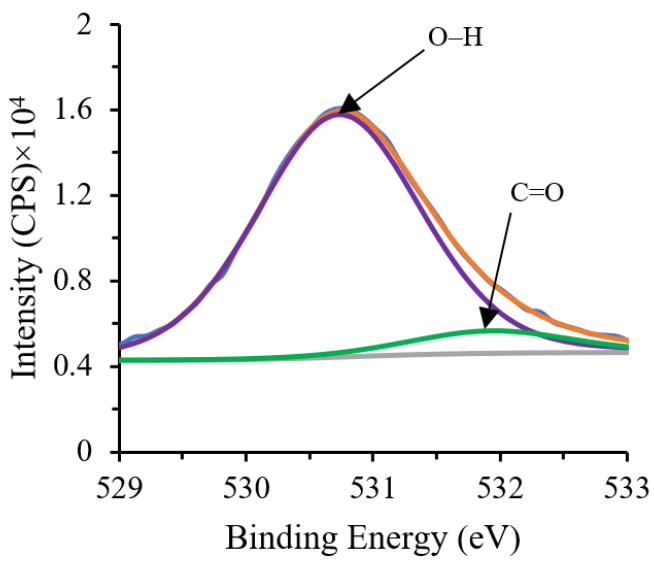

(e)

Figure 2. (a) FTIR analysis of undoped (black line) and N-CDs (red line), (b) X-ray photoelectron spectrum (XPS) of N-CDs, (c) high-resolution XPS for $\mathrm{C}_{1 \mathrm{~s}}$, (d) high-resolution XPS spectra for $\mathrm{N}_{1 \mathrm{~s}}$ and (e) high-resolution XPS spectra for $\mathrm{O}_{1 \mathrm{~s}}$. 


\subsection{Optical Properties of $\mathrm{N}-\mathrm{CD}$ s}

The UV-vis absorption spectra of the undoped CDs and N-CDs are presented in Figure 3a. It is shown that both curves exhibited long absorption edge in both UV and visible region (300-600 nm) without any noticeable sharp absorption peaks, as mostly observed in CDs [63]. A typical absorption peak at $294 \mathrm{~nm}$ was observed in N-CDs, which was assigned to the $\pi-\pi^{*}$ transition of $\mathrm{sp}^{2}$-hybridized carbon core $(C-C)$ [63]. Besides that, peaks were observed at 312 and $350 \mathrm{~nm}$ in undoped CDs and $\mathrm{N}-\mathrm{CDs}$, respectively, which may have been attributed to $\mathrm{n}-\pi^{*}$ of non-conjugated electron orbitals, originated from the oxygen functionalization $(\mathrm{C}=\mathrm{O})$ bonds and amino groups at the surface (in case of $\mathrm{N}-\mathrm{CDs}$ ) similar to previous studies [21].

The colour of the well-dispersed CDs and N-CDs (inset of Figure 3a) exhibited blue and greenish emission, respectively while irradiated with $365 \mathrm{~nm}$ ultraviolet (UV) light, indicating the dependence of the PL emission on the particle sizes and the $\mathrm{sp}^{2}$-carbon framework. It was also proven that both larger conjugated system and the higher graphitization of nitrogen-doped polyaromatic structure played a main role in reducing the energy bandgap, and hence results in red-shifted of PL emission $[3,20,64]$. The strong greenish photoluminescence of $\mathrm{N}-\mathrm{CDs}$ can be clearly noticed with the naked eye, making them promising applications in a wide range of areas, such as bioimaging, biomedical, and chemical sensing.

The PL spectra of undoped and N-CDs solutions excited at $350 \mathrm{~nm}$ is presented in Figure $3 \mathrm{~b}$. Based on the graph, it can be seen that $\mathrm{N}-\mathrm{CDs}$ had a stronger emission compared to the undoped CDs with the same absorbance. Besides, there was red-shift of the PL maxima of N-CDs. The inset of Figure $3 \mathrm{~b}$ shows that the maximum PL QY of N-CDs in aqueous solution was approximately $44 \%$. This efficiency was higher than the maximum fluorescence QY of the undoped CDs, which was $7.54 \%$. Meanwhile, it was proven in this study that LPEI was non-emissive when it was hydrothermally synthesized on its own. This indicated the significant role of using LPEI as surface passivating agent/nitrogen source for the enhancement of PL properties of CDs.

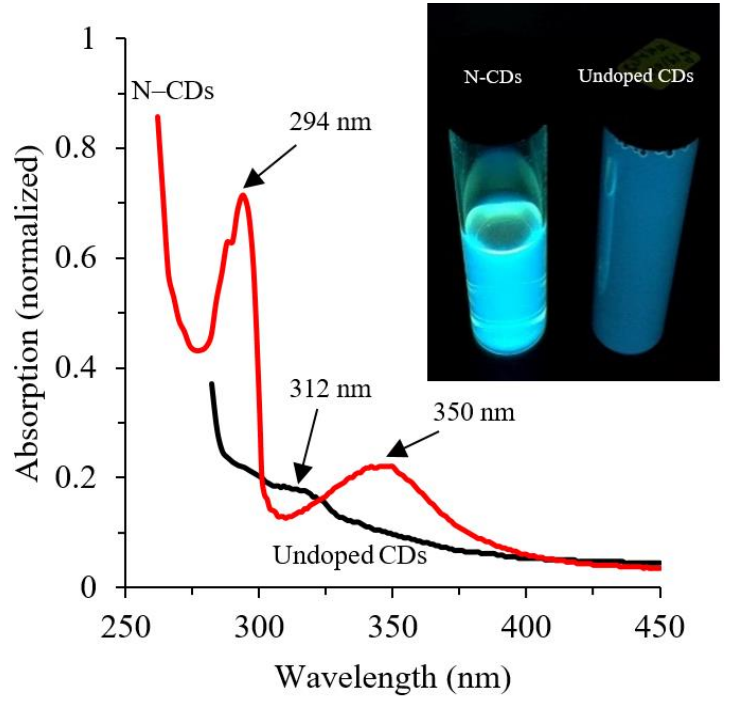

(a)

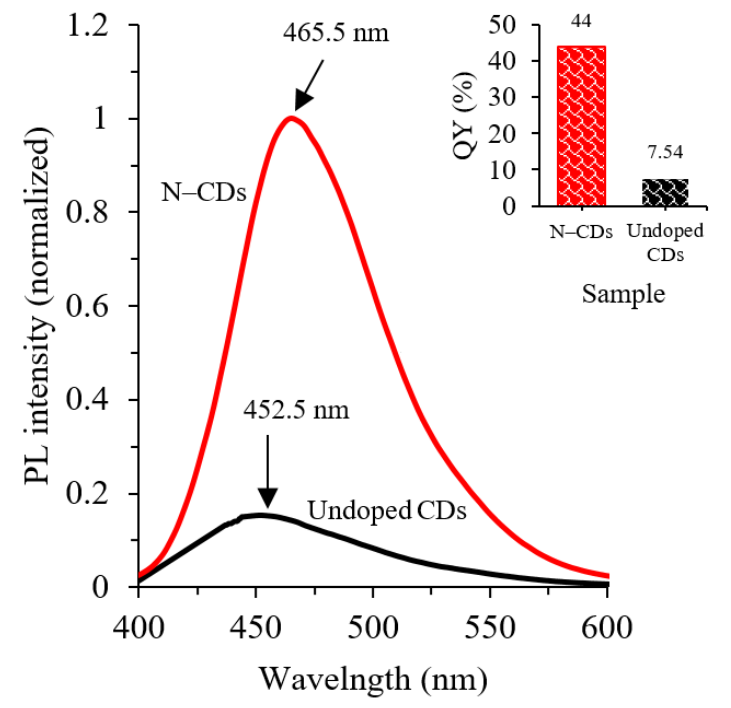

(b)

Figure 3. Cont. 


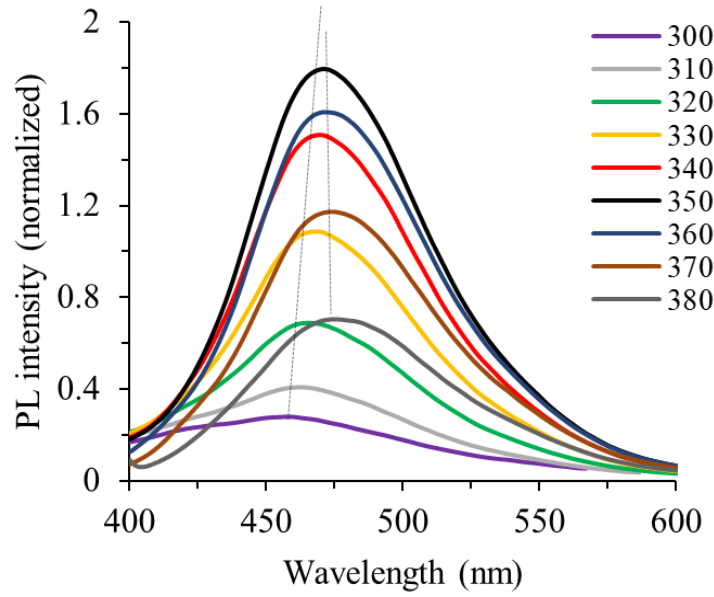

(c)

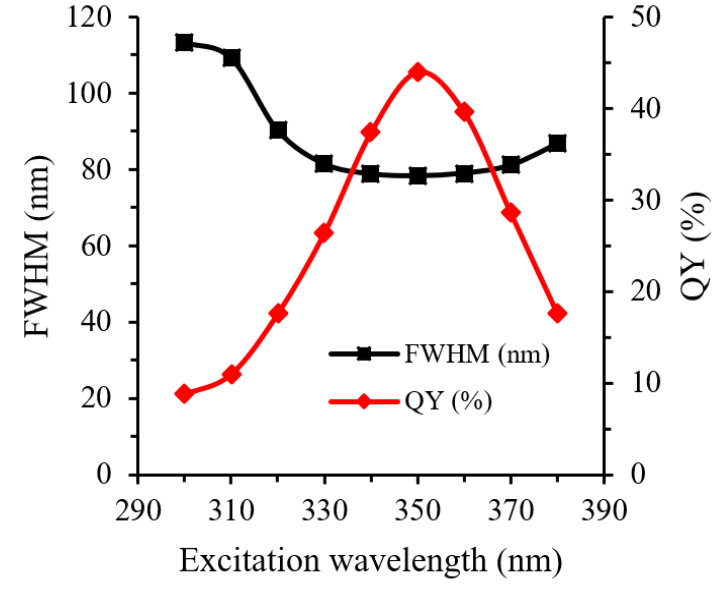

(d)

Figure 3. (a) Absorption spectra of undoped and N-CDs, (b) fluorescence PL spectra of undoped and N-CDs excited at $350 \mathrm{~nm}$, with $\mathrm{A}_{350}=0.04$, (c) PL spectra of N-CDs under various excitation wavelengths (300-380 $\mathrm{nm}$ ) and (d) emission full width at half maximum (FWHM) and quantum yield (QY) as a function of excitation wavelength. The inset in panels (a) for the corresponding photographs under $365 \mathrm{~nm}$ UV light and (b) the corresponding calculated QYs.

The selective luminescence spectrum of N-CDs is illustrated in Figure 3c. When excited by light with different excitation values (300-380 nm), wide emission features could be observed, in which the excitation increased to a maximum of $350 \mathrm{~nm}$ and then reduced rapidly afterwards. Blue-shift of emission peaks was shown when the excitation wavelength was below 350 nm. However, red-shift was present at 472.5 when excitation wavelength varied from 350 to $380 \mathrm{~nm}$. This excitation dependence/independence emission wavelength was most likely due to the surface state emission originated from the abundant of reactive oxygen/nitrogen functional groups, which affects the energy bandgap of N-CDs [18,65]. Additionally, the selective luminescence excitation wavelength was also possibly due to the size variation of $\mathrm{sp}^{2}$-hybridized carbon framework and the graphitic nitrogen content $[56,64,65]$.

Figure $3 \mathrm{~d}$ shows the full width at half maximum (FWHM) of the emission spectra as a function of excitation wavelength. A slight change of excitation wavelength in the range of 320-380 nm were observed with a minimum FWHM of $78.3 \mathrm{~nm}$ at $\lambda_{\mathrm{ex}}=350 \mathrm{~nm}$. Meanwhile, a gradual increase in the FWHM could be seen when the excitation value was lower than $320 \mathrm{~nm}$. This suggested the suitability of using these nanomaterials in broad range of analytical applications [66]. Moreover, Figure 3d shows that PL QY was highly dependent on the excitation wavelength. Specifically, the rise in the QY occurred with the increase of excitation wavelength, reaching the maximum of $\sim 44 \%$ at $350 \mathrm{~nm}$ excitation. However, further increase of excitation wavelength had a negative effect on the fluorescence QY. Comparing the dependence of QY and FWHM indicated a trade-off between QY and FWHM. There was a similarity between the peak of absorption and excitation wavelength, which corresponded to the maximum intensity of emission at $350 \mathrm{~nm}$. This similarity demonstrated that non-emitting absorption arised in N-CDs. The N-CDs had a large Stokes shift of around $115.5 \mathrm{~nm}$, which is an advantage for bio-imaging applications [3].

The formation of N-CDs, which was investigated in this study, took place via five pathways: dehydration, polymerization, aromatization, nucleation and growth processes [55,67]. A schematic representation of the fundamental understanding of the N-CDs formation from CMC and LPEI through HTC is shown in Figure S1. More details on the proposed chemical reactions for the formation steps of N-CDs can be found in the Supplementary Materials. 
3.4. Effect of N-CDs Concentration, $p H$, Surface Charge, Irradiation Time, Ionic Strength and Storage Time on the Fluorescence of $N-C D s$

Despite the superior optoelectronic properties of N-CDs, there are insufficient studies on the intensity wavelength and PL property as a function of N-CDs concentration, in which PL is usually measured in most works of literature without any dilution. Prior to applying N-CDs for further applications, several dilutions (10,50 and 100-fold) of the originally obtained N-CDs were carried out, as shown in Figure 4. It could be seen that the intensity wavelength and the PL emission of the N-CDs were highly dependent on the concentration of N-CDs solution. As shown in Figure $4 \mathrm{a}$, the emission peaks were constant before and after the addition of 10-fold dilution factor, with emission maxima of $465.5 \mathrm{~nm}$. However, gradual blue-shift in the emission maxima (from 465.5 to $448 \mathrm{~nm}$ ) were observed with continuous 50 and 100-fold dilution with DI water. This blue-shift could be clearly seen in the normalized fluorescence emission spectra (inset of Figure 4), in which different dilutions were excited under a similar wavelength value of $350 \mathrm{~nm}$.

A progressive rise in the PL intensity of the emission peak could be seen with the reduced N-CDs concentration, as shown in Figure $4 \mathrm{a}$. The corresponding images of N-CDs without and with DI dilution (10, 50 and 100-fold) under daylight and UV-light, respectively are shown in Figure 4b. The colour of aqueous N-CDs under ambient light gradually changed from dark yellowish to transparent with the increased addition of DI water into the obtained N-CDs. The results regarding the irradiation of the samples by the UV-light $\left(\lambda_{\mathrm{ex}}=365 \mathrm{~nm}\right)$ was in agreement with the results of PL spectra, in which the addition of DI water dilution by 10 -fold led to the highest PL emission, in comparison to the concentrated N-CDs.

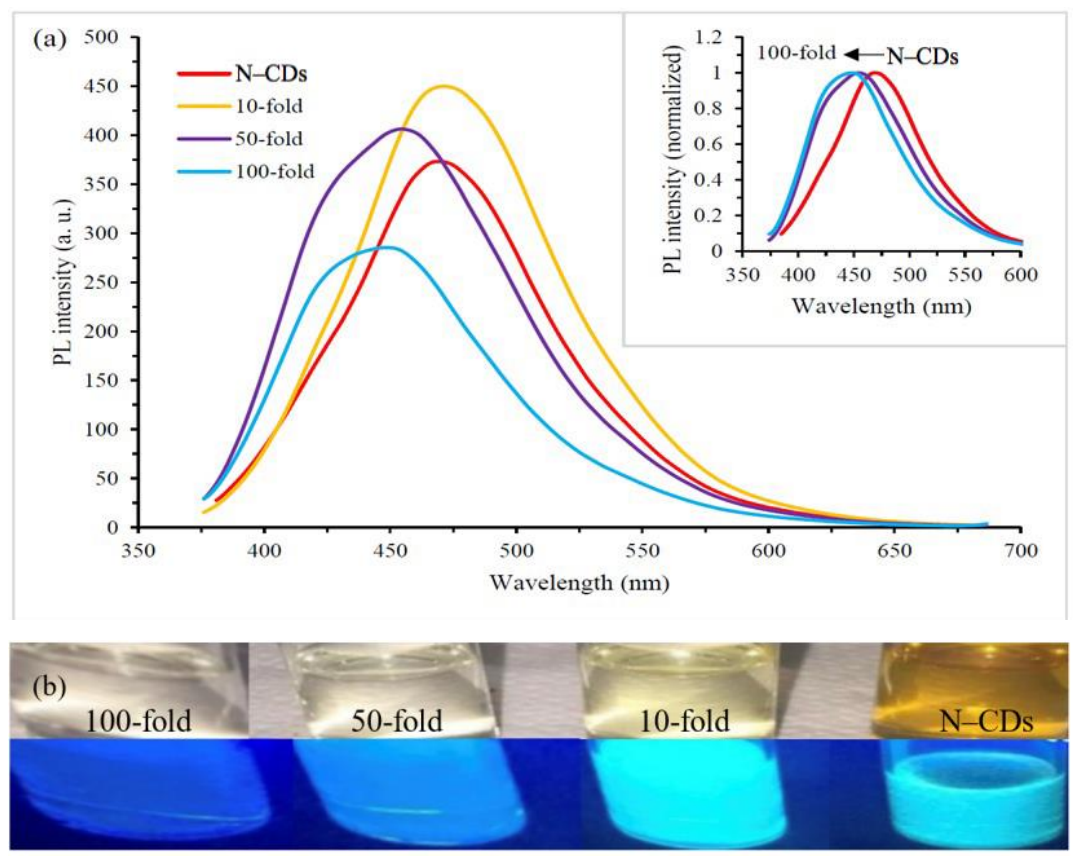

Figure 4. PL spectra of the N-CDs at different dilution factors starting with N-CDs, 10, 50 and 100-fold (a) and the corresponding digital images at different dilutions under daylight (above) and UV-light $(365 \mathrm{~nm})$ (below) (b). Inset shows the normalized fluorescence emission spectra of N-CDs at different dilutions with the excitation wavelength of $350 \mathrm{~nm}$.

The variation of emission phenomena could be explained by the combination of Van der Waals forces to create nano-sized clusters at a high-concentration solution. This would lead to an increased polarity on the surfaces of aggregated N-CDs. However, with the addition of DI water of up to 10-fold dilution into the $\mathrm{N}-\mathrm{CD}$ solution, these aggregated $\mathrm{N}-\mathrm{CD}$ s were separated into monodispersed N-CDs. As a result, the polarity and the emission enhancement of $\mathrm{N}-\mathrm{CD}$ s would be reduced [2]. Overall, it was 
suggested from the results that the adjustment of aqueous $\mathrm{N}-\mathrm{CD}$ s concentration was the key point to tune the emission wavelength and fix the emission peak, in which the high polarity nanoclusters may lead to diverse emission phenomena [68].

The PL of the numerically optimized N-CDs was further studied by identifying the influence of $\mathrm{pH}$, surface charge, time of exposure, ionic strength and storage time on the PL of N-CDs. The $\mathrm{pH}$ value of the original aqueous dispersion of $\mathrm{N}-\mathrm{CD}$ s was around 7.6. The influence of $\mathrm{pH}$ level on the PL of N-CDs is shown in Figure 5a. PL emission at different pH values was analysed by adjusting aqueous $\mathrm{N}-\mathrm{CD}$ s with $\mathrm{NaOH}$ and $\mathrm{HCl}$. It can be said that when $\mathrm{pH}$ is about 3 , the highest $\mathrm{PL}$ emission intensity could be reached. However, the PL emission would then weaken beyond this value until the $\mathrm{PL}$ emission turned to the lowest value under $\mathrm{pH}>12$. It was also observed that the emission was almost maintained completely with the $\mathrm{pH}$ value ranging from 6 to 12 (inset of Figure 5a). This proved the stability of the obtained $\mathrm{N}-\mathrm{CD}$ s under a wide range of $\mathrm{pH}$ values. Moreover, red-shift in the emission maxima from $468 \mathrm{~nm}$ to $475 \mathrm{~nm}$ was observed at $\mathrm{pH}=3$. However, the emission maxima were constant under other $\mathrm{pH}$ conditions. This phenomenon could be explained by the surface state, in which various hydrophilic containing groups like $-\mathrm{OH}$ and $-\mathrm{COOH}$ are subjected to deprotonation at $\mathrm{pH}>12$. This process would form anions which could change the PL position and intensity due to the N-CDs surrounded by anion aggregate $[20,69,70]$.

The $\mathrm{pH}$ mechanism of N-CDs was further evaluated by zeta potentials $(\xi)$ study. Based on the results shown in Figure $5 b$, $\xi$ potential changes from $7 \mathrm{mV}$ to $-47 \mathrm{mV}$ with the increase of $\mathrm{pH}$ value from 3 to 13. A linear relationship (inset of Figure 5b) between $\xi$ potential and $\mathrm{pH}(3-13)$ could be expressed as $\xi=-5.6436 \mathrm{pH}+29.432\left(R^{2}=0.9654\right)$. The high $\xi$ potential confirmed the reversible protonation and deprotonation of the reactive containing groups, especially $-\mathrm{NH}$ and $-\mathrm{COOH}$, on the surface of $\mathrm{N}-\mathrm{CD}$ s which facilitated the negatively-charged zeta. As a result, the electrostatic interactions between the N-CDs and negatively-charged surface could prevent the aggregation of the N-CDs and hence stabilize them [71]. $\xi$ potential measurement indicated that the obtained N-CDs had an isoelectric point at $\mathrm{pH}$ 5.7. The overall results of $\xi$ potential study support very well the data obtained from FTIR and XPS analysis. It is worth mentioning that the $\xi$ potential of the aqueous $\mathrm{N}-\mathrm{CDs}$ of the present work $(-47 \mathrm{mV})$ was higher than that of the CDs obtained using different passivation agents such as xylan/ $\mathrm{NH}_{4} \mathrm{OH}(-4.26 \mathrm{mV})$ [72] and S-CDs from thiomalic acid/ $\mathrm{H}_{2} \mathrm{SO}_{4}(-42 \mathrm{mV})$ [73]. This indicated the highly negatively-charged groups presented over the N-CDs surface which imparted higher stability and dispersibility.

The characteristics of PL intensity and the UV exposure time up to $180 \mathrm{~min}$ is presented in Figure S2a. The PL intensity exhibited no significant decrease after 180 min of illumination, retaining about $97 \%$ of their original PL emission. This suggested that the N-CDs were highly resistant to photobleaching. Similar to the effect of UV exposure time, the $\mathrm{NaCl}$ and $\mathrm{KCl}$ concentrations showed no obvious effect on the PL emission even when the concentration of $\mathrm{NaCl}$ and $\mathrm{KCl}$ was up to $1.0 \mathrm{M}$ (Figure S2b,c). This demonstrated the excellent stability of the LPEI-CDs under high-salt conditions. Moreover, with the rise of temperature from $25^{\circ} \mathrm{C}$ to $60{ }^{\circ} \mathrm{C}$ (Figure S2d), PL intensity retention of around $97.8 \%$ was observed. The effect of storage time on the PL intensity of N-CDs was also investigated. As shown in Figure S3a, the obtained N-CDs were stable for more than six months without any aggregation. The residual PL intensity of the $\mathrm{N}-\mathrm{CD}$ retained $95.4 \%$ of their original value after six months (Figure S3b). The outstanding photostability of N-CDs was possibly due to their small size effect, graphitic nitrogen content and the reactive containing groups which were formed on the N-CDs surface. The long shelf-life of N-CDs suggested that there is a possibility of applying these $\mathrm{N}-\mathrm{CDs}$ for commercial applications, such as biological labelling and fluorescent chemical sensing. 


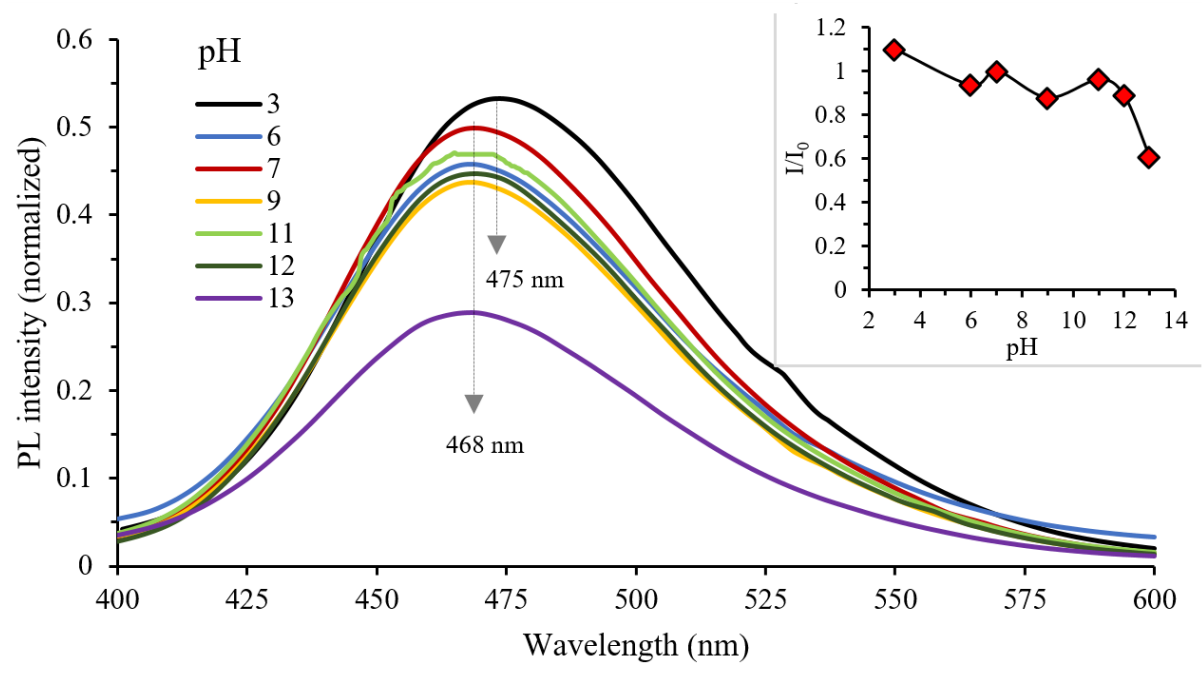

(a)

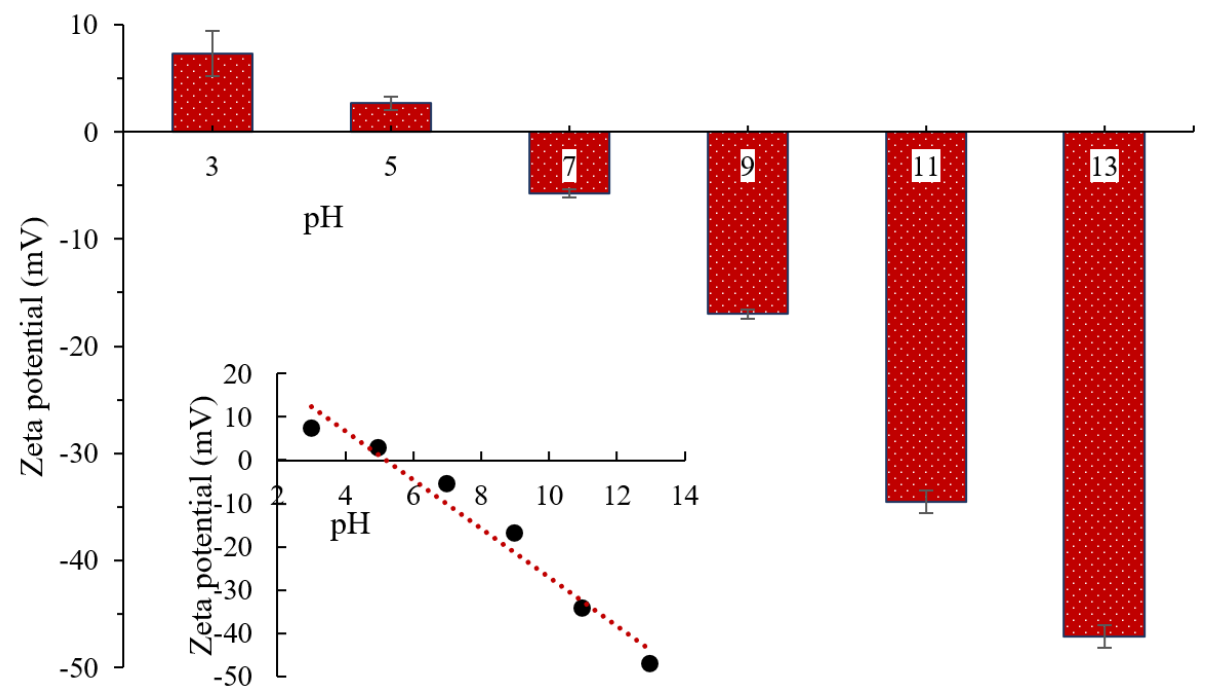

(b)

Figure 5. (a) The emission dependence of $\mathrm{N}-\mathrm{CDs}$ on $\mathrm{pH}$ values with $\lambda_{\mathrm{ex}}=350 \mathrm{~nm}$ and (b) zeta potential study of $\mathrm{N}-\mathrm{CDs}$ at various $\mathrm{pH}$ values. Inset: (a) the effect of different $\mathrm{pH}$ values on the relative intensity and (b) the linear relationship between $\mathrm{pH}$ and zeta potential.

\subsection{Fluorescence Quenching for $\mathrm{Cu}^{2+}$ Sensing}

FTIR and XPS studies confirmed the existence of oxygen/nitrogen-containing groups over the $\mathrm{N}-\mathrm{CDs}$ surface. These groups have good affinity to interact with metal ions by forming coordination bonds, in which donation of electron pair from the functional terminal to the centre metal ions can occur. Hence, the selectivity of the obtained $\mathrm{N}-\mathrm{CD}$ s towards the most commonly found metal ions in water system was examined as presented in Figure $6 \mathrm{a}$. $I$ and $I_{0}$ represent the PL intensities of the probes at $465.5 \mathrm{~nm}$ in the absence and presence of $50 \mu \mathrm{M}$ of various metal cations, respectively. It is shown that the addition of $\mathrm{Cu}^{2+}$ caused a drastic reduction in the PL emission of N-CDs with over $50 \%$ of quenching efficiency, while less was noticed by adding other metal ions. The above results indicated that only $\mathrm{Cu}^{2+}$ had higher chelating kinetics with $\mathrm{N}-\mathrm{CDs}$ owing to the higher binding of $\mathrm{Cu}^{2+}$ to $\mathrm{N}-\mathrm{CDs}$ at the $-\mathrm{OH},-\mathrm{COO}^{-}$, and/or $-\mathrm{NH}$, resulting in the fluorescence quenching effect [74]. 


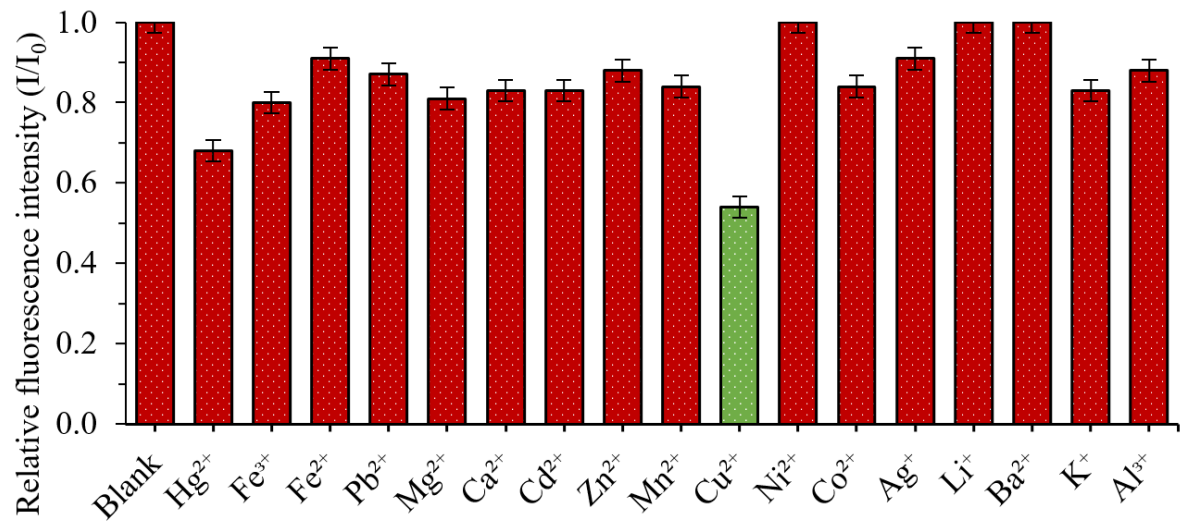

Metal ions

(a)

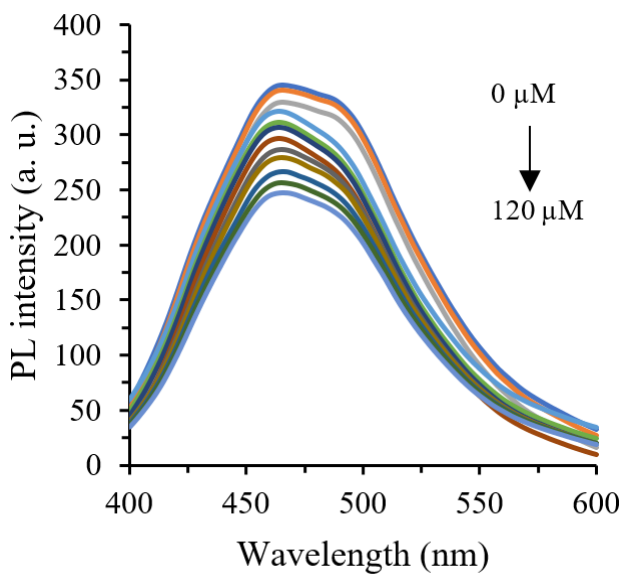

(b)

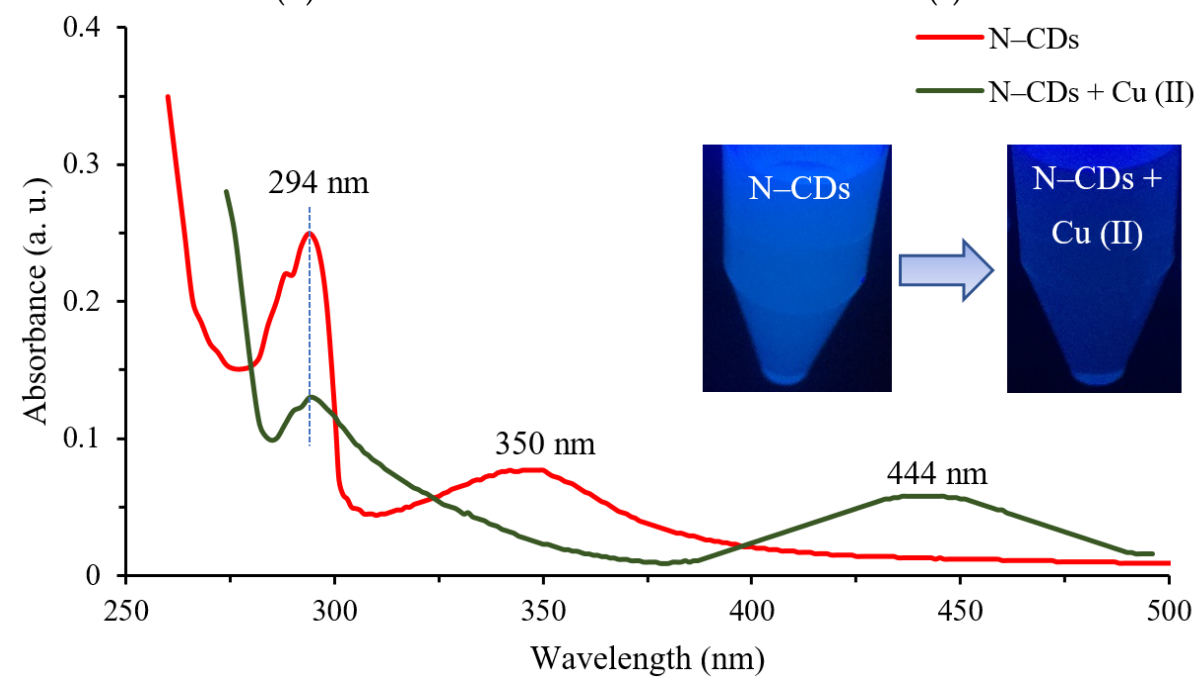

(d)

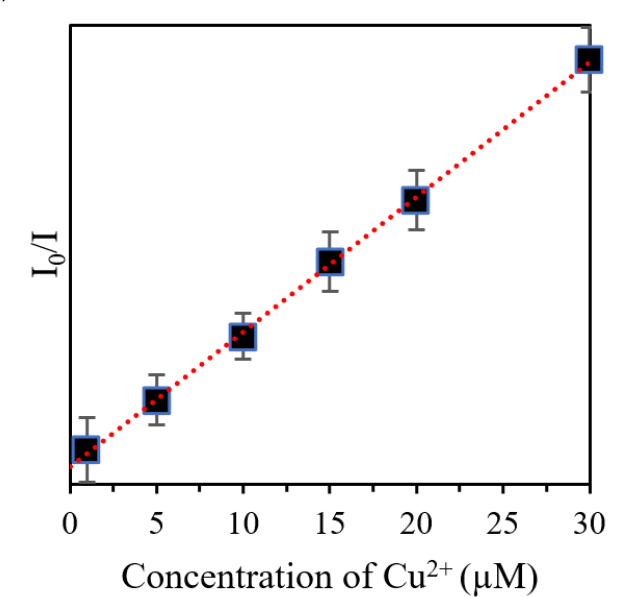

(c)

Figure 6. (a) Relative fluorescence intensity of aqueous $\mathrm{N}-\mathrm{CDs}$ at $\lambda_{\mathrm{em}}=465.5 \mathrm{~nm}$ in the presence of $50 \mu \mathrm{M}$ of various individual metal ions, (b) PL emission spectra of aqueous N-CDs in the presence of different concentration of $\mathrm{Cu}^{2+}(0,15,30,50,70,90$ and $120 \mu \mathrm{M})$, (c) a linear correlation of $\mathrm{I}_{0} / \mathrm{I}$ ratio and the concentration of $\mathrm{Cu}^{2+}$, where $\mathrm{I}_{0}$ and I represent the fluorescence intensity in the absence and in the presence of $\mathrm{Cu}^{2+}$ ion, respectively and (d) UV-Vis absorption spectra of N-CDs before (red line) and after (black line) the addition of $700 \mu \mathrm{M} \mathrm{Cu}$ (II). Inset shows the corresponding photo images of sensing under UV lamp. 
According to the response selectivity of $\mathrm{CDs}$ to $\mathrm{Cu}^{2+}$ among other metal ions, three factors may be attributed for this: (i) copper ions exhibit the highest absorption affinity towards the carbon nanostructure among other transition metals, which is the prerequisite for the effective fluorescence quenching for the $\mathrm{CDs} / \mathrm{Cu}^{2+}$ system [75]; (ii) the strong fluorescence quenching for $\mathrm{CDs} / \mathrm{M}^{n+}$ (M: metal) system means the efficient electron transfer from the excited state of $\mathrm{CDs}$ to $\mathrm{M}^{n+}$, then back to the ground state of $\mathrm{CDs}$, which requires an appropriate potential of $\mathrm{M}^{\mathrm{n}+} / \mathrm{M}$ (i.e., more negative than the potential of the hole on the CDs and more positive than that of the electron on the CDs). From the standard formal potential $\left(E_{0}\right)$ of $\mathrm{M}^{n+} / \mathrm{M}$, the redox potential of $\mathrm{Cu}^{2+} / \mathrm{Cu}^{+}\left(\mathrm{or} \mathrm{Cu}^{2+} / \mathrm{Cu}\right)$ was possibly optimum for the electron transfer from CDs compared to other reference metal ions [76]; (iii) the good oxidisability of $\mathrm{Cu}^{2+}$ makes $\mathrm{Cu}^{2+}$ the most appropriate receptor for the transferred electron from QDs [77].

In order to achieve high analytical performances, several sensing conditions, including response time and $\mathrm{pH}$ values were analysed and optimized prior to sensitivity measurements. The effect of time durations (from 1 to $25 \mathrm{~min}$ ) on the PL quenching of N-CDs is presented in Figure S4a. Highest quenching degree in the presence of $50 \mu \mathrm{M} \mathrm{Cu}^{2+}$ was observed within $1 \min \left(\lambda_{\max }=350 \mathrm{~nm}\right)$. However, less to no effect was noticed upon increasing sensing time, indicating the rapid detection signal of LPEI-CDs towards $\mathrm{Cu}$ (II). A fast response time of $1 \mathrm{~min}$, much faster than the reported ones [69-71,78], made the LPEI-CDs quick-detection sensors for $\mathrm{Cu}^{2+}$ in aqueous water.

The $\mathrm{pH}$ value of the $\mathrm{N}-\mathrm{CDs}$ solution in the presence of $\mathrm{Cu}^{2+}$ was another key factor that affected the sensing system. Thus, the effect of $\mathrm{pH}$ values (ranging from 3-13) on the PL quenching of N-CDs was evaluated and the results are shown in Figure S4b. The PL response of N-CDs to $\mathrm{Cu}^{2+}$ is evidently weakened in strong acid or alkaline conditions, which should be due to the protonation of the carboxyl group under acidic conditions or generation of $\mathrm{Cu}(\mathrm{OH})_{2}$ precipitation under alkaline conditions, respectively [79]. Based on the above findings, the sensitivity experiments were performed under optimal conditions of $1 \mathrm{~min}$ incubation time at $\mathrm{pH} 7$.

In order to investigate the sensitivity of the $\mathrm{N}-\mathrm{CDs}$ as a probe for $\mathrm{Cu}$ (II) ions sensing, analytical characteristic study was conducted. The relative intensity at $465.5 \mathrm{~nm}$ was utilised as the sensing signal for the sensitivity study. The PL of N-CDs was quenched accordingly and dependently to the concentration of the $\mathrm{Cu}$ (II) added to the N-CDs. However, the degree of change in the signal intensity corresponding to the concentration of $\mathrm{Cu}$ (II) was found to be non-linear. The variation of $\mathrm{PL}$ intensity of the aqueous $\mathrm{N}-\mathrm{CDs}$ in the presence of different concentration of $\mathrm{Cu}^{2+}$ is shown in Figure $6 \mathrm{~b}$. A gradual quenching in the PL intensity was shown with the rise of $\mathrm{Cu}$ (II) concentrations (from 0-120 $\mu \mathrm{M}$ ). Based on the Stern-Volmer equation [80], the linear relationship between the relative PL intensity ratio $\left(I_{0} / I\right)$ versus the concentration of $\mathrm{Cu}$ (II) within the range of $1-30 \mu \mathrm{M}$ was obtained (Figure 6c), with a correlation coefficient of $R^{2}=0.9994$. The fluorescence quenching efficiency of the $\mathrm{Cu}$ (II) would be described through to the following equation:

$$
\mathrm{I}_{0} / \mathrm{I}=1.0476+0.0056 \times \mathrm{C}_{\mathrm{Cu}^{\prime}}^{2+}
$$

where $I_{0}$ and $I$ are the fluorescence intensity in the absence and presence of $\mathrm{Cu}$ (II) ion, respectively. The detection limit (LOD) of $\mathrm{Cu}^{2+}$ (at a Signal/Noise of 3) was estimated to be $0.93 \mu \mathrm{M}$ based on $\mathrm{LOD}=3 \mathrm{~S} / \mathrm{K}$, where $\mathrm{K}$ refers to the calibration curve slope and $\mathrm{S}$ represents the standard deviation of the blank. Table 1 outlines the performance parameters of the recently reported work done for the sensing of $\mathrm{Cu}^{2+}$. A low detection limit of $5 \mathrm{nM}$ and wide detection range of $5 \mathrm{nM}-100 \mu \mathrm{M}$ was obtained for CdSe QDs, but the introduction of toxic element inhibits their practical application [50], though it can be enhanced by cladding with a silica shell [76].

As a contrast, CDs are excellent fluorescence probes due to their non-toxicity, high stability and sensitivity, but some shortcomings inhibit their ion detection application, such as long response time of more than $10 \mathrm{~min}[77,81-83]$, narrow detection interval of only two orders of magnitude $[82,84,85]$, high detection limit $[80,83,86,87]$ or complex probe synthesis $[83,85]$. The complicated processing could be avoided during the synthesis of the $\mathrm{N}$-doped CDs, but these $\mathrm{N}-\mathrm{CDs}$ exhibited narrow detection 
intervals of $0.3-1.6 \mu \mathrm{M}$ [87]. In comparison to a number of previous reports, the present nanoprobe had beneficial performance in terms of detection interval, response time and LOD as well as QY.

Table 1. Summary of some fluorescent probes for $\mathrm{Cu}^{2+}$ sensing.

\begin{tabular}{ccccc}
\hline Probe & $\begin{array}{c}\text { Response Time } \\
(\mathbf{m i n})\end{array}$ & $\begin{array}{c}\text { Response Interval } \\
(\boldsymbol{\mu M})\end{array}$ & LOD $(\boldsymbol{\mu M})$ & Reference \\
\hline CDSe & 5 & $0.005-100$ & 0.005 & {$[50]$} \\
CdSe/Zns@CDs & - & $1-100$ & 1 & {$[77]$} \\
CDs from sago waste & - & $0-47$ & 7.78 & {$[76]$} \\
CDs from grass & 10 & $5 \times 10^{-5}-50$ & 0.001 & {$[82]$} \\
CDs from peanut shell & 10 & $0-5$ & 4.8 & {$[83]$} \\
CDs from MS & 15 & $0-10$ & $0.23 \times 10^{-3}$ & {$[81]$} \\
CDs from CA & - & $0.37-2.5$ & 0.63 & {$[85]$} \\
N-CDs from EDA/P $\mathrm{O}_{5}$ & - & $10-400$ & 10 & {$[87]$} \\
N-CDs from D-glucose/EDA & 10 & $10-100$ & 1.8 & {$[84]$} \\
N-CDs from CA/NaBH $4 /$ PEI & $<1$ & $0-80$ & 5.3 & {$[79]$} \\
N-CDs from CA/PEI & - & $0.3-1.6$ & 0.12 & {$[80]$} \\
N-CDs from CMC/LPEI & 1 & $1-30$ & 0.9 & This work \\
\hline
\end{tabular}

Note: MS: mesoporous silica, $\mathrm{CA}$ : citric acid, $\mathrm{P}_{2} \mathrm{O}_{5}$ : phosphorus pentoxide, EDA: ethylenediamine, $\mathrm{NaBH}_{4}$ : sodium borohydride, PEI: polyethyleneimine.

The maximum recommended level of $\mathrm{Cu}$ (II) ions in drinking water are $2 \mathrm{mg} / \mathrm{L}$, equivalent to $47.2 \mu \mathrm{M}$ and $1.3 \mathrm{mg} / \mathrm{L}$, equivalent to $20.46 \mu \mathrm{M}$ as suggested by the World Health Organization and Environmental Protection Agency, respectively [48]. The low LOD for $\mathrm{Cu}$ (II), which was obtained through the proposed sensing probe in this research, could be explored and applied for its potential in detection of $\mathrm{Cu}$ (II) in water samples.

\subsection{Investigation of Sensing Mechanism}

Based on the earlier observations [88-90], the high affinity of $\mathrm{N}-\mathrm{CDs}$ by $\mathrm{Cu}^{2+}$ might be attributed to the cupric amine complex, which could be formed by the coordination of $\mathrm{Cu}^{2+}$ ions with active amino groups around N-CDs. PL intensity reduction might be resulted from this stable complex leading to $\mathrm{N}-\mathrm{CDs}$ aggregation. To prove the aforementioned assumption, different spectroscopic measurements were carried out to study the characteristics of $\mathrm{N}-\mathrm{CDs}$ in the presence of $\mathrm{Cu}$ (II).

As seen in Figure S5, there was a significant increase by $\sim 600 \mathrm{~nm}$ in the average size of $\mathrm{N}-\mathrm{CDs}$ after $\mathrm{Cu}$ (II) was added. This indicated the aggregation of $\mathrm{N}-\mathrm{CDs}$ chelated by $\mathrm{Cu}$ (II) through the formation of $\mathrm{Cu}$ (II)-N-CDs complexes. Furthermore, the zeta potential value increased from -7.74 to $20.97 \mathrm{eV}$ after the addition of $700 \mu \mathrm{M} \mathrm{Cu}$ (II), as shown in Figure S6. This increase suggested that the negative charges of $\mathrm{N}-\mathrm{CDs}$ were neutralized with the positive charges of $\mathrm{Cu}$ (II) due to the electrostatic effect. UV-Vis spectroscopy of N-CDs was also measured in the presence of $700 \mu \mathrm{M} \mathrm{Cu}$ (II) as shown in Figure $6 \mathrm{~d}$. It can be observed that the absorption of the N-CDs after the addition of $\mathrm{Cu}$ (II) exhibited a new band at $444 \mathrm{~nm}$ and the absorption peak at $350 \mathrm{~nm}$ totally disappeared. This additional band could be ascribed to the charge transfer from $\mathrm{N}$ atom to the $\mathrm{d}$ orbitals of $\mathrm{Cu}$ (II) since the higher absorption energy peak, which was originated from $\mathrm{sp}^{2}$-hybridized carbon core $(\mathrm{C}=\mathrm{C})$, was unaltered. Moreover, the fluorescence reduction of $\sim 50 \%$ supported the assumption that the quenching mechanism was caused by the binding effect of $\mathrm{N}$ species and not differently sized LPEI-CDs as its reduction was not fully quenched [87]. These above results confirmed that $\mathrm{Cu}$ (II) could form coordinate covalent bonds with the active organic $\mathrm{N}$ sites that fully covered the surface of LPEI-CDs, which enabled the design of "fluorescence turn-off" sensors for the rapid determination of $\mathrm{Cu}$ (II).

\subsection{Analysis of Water Samples}

In order to assess the practicality of the developed sensing probe, the detection of $\mathrm{Cu}$ (II) was investigated in tap water using a standard addition method. The experimental results of the blank and 
spiked real water samples before and after the addition of $\mathrm{Cu}$ (II), respectively are presented in Table 2. It is shown that there was no $\mathrm{Cu}$ (II) found in the blank sample. The results of spiked samples showed that the percentage of recoveries were between $97.03 \%$ and $105.82 \%$ and the RSD were from $1.49 \%$ to $2.43 \%$, which was satisfactory for the application. In comparison to the previous works [74,91], our present sensing probe was of great advantage not only in terms of highly QY that were obtained using mild conditions but also of being less toxic compared to metal-based QDs. This suggests the reliability of applying the developed $\mathrm{N}-\mathrm{CDs}$ as probes for the determination of $\mathrm{Cu}$ (II) in real water.

Table 2. Determination of $\mathrm{Cu}(\mathrm{II})$ in tap water using N-CDs.

\begin{tabular}{cccc}
\hline Added $(\mu \mathrm{M})$ & Found in Tap Water $(\mu \mathrm{M})$ & Recovery $(\%)$ & $\operatorname{RSD}(\boldsymbol{n}=\mathbf{3}, \mathbf{\%})$ \\
\hline 0 & $\mathrm{ND}^{*}$ & - & - \\
15 & 16 & 105.82 & 2.43 \\
30 & 30.14 & 99.07 & 0.87 \\
50 & 49 & 97.03 & 1.49 \\
\hline
\end{tabular}

* ND: not detected.

\subsection{Composite Film}

Up to now, exploring N-CDs for novel applications is still a hot topic area due to their fascinating properties like fluorescent long-shelf time, resistance to photobleaching and great transparency in the visible light. However, the immobilization of N-CDs in solid-state cases is still challenging since N-CDs suffers from self-quenching property after the fabrication process. It is well known that superior solid-state PL emission of N-CDs is of great advantage for light-emitting diode (LED) fields. Thus, a polymer matrix was developed using PVA/N-CDs composite film to evaluate the workability of non-ionic polymer to bind colloidal particles onto a solid surface. PVA was chosen as the polymer host because it is a non-toxic, hydrophilic, optical transparency, bioadhesive polymer [92,93].

As shown in Figure 7a,b, the PVA film without the immobilization of N-CDs had no PL emission while PVA/N-CDs films exhibited a bright greenish PL under UV-light irradiation. This indicated that the N-CDs were properly encapsulated in the PVA film. The presence of the active hydrogen-containing groups $(-\mathrm{COOH},-\mathrm{OH}$ and $-\mathrm{NH})$ on the $\mathrm{N}-\mathrm{CDs}$ surface could form cross-linking chains. This led to the hydrogen bond formation from their plenty interactions with PVA [92,94]. In contrast to the aqueous N-CDs solution shown in Figure 3c, only an excitation independent feature was observed from the solid film upon various excitation wavelengths (Figure 7c), which is consistent with previous finding [95]. Additionally, the excitation/emission maxima of PVA/N-CDs film was red-shifted by 10/3 nm, respectively (Figure S7). This phenomenon may belong to PVA environment, which was a different case compared to the aqueous solution [96].

FTIR spectra were conducted in order to investigate the changes in the structure and surface functionalities between the obtained N-CDs solution and PVA/N-CDs solid film, as presented in Figure S8. In contrast to N-CDs solution, significant changes were observed after immobilization of N-CDs solution into the PVA host. To be specific, new peaks at 1438.25 and $1738.43 \mathrm{~cm}^{-1}$ were ascribed to $C=C$ and $C=N$ groups, respectively [95]. Meanwhile, the shifting and rise of $C-N$ from 1266 to $1368 \mathrm{~cm}^{-1}$, implied an increase in graphitic structure after the encapsulation process. Furthermore, the change in position and shape of the $\mathrm{C}-\mathrm{H}$ bending of $\mathrm{N}-\mathrm{CD}$ s solution from 725.11 to $771.76 \mathrm{~cm}^{-1}$ confirmed the formation of strong hydrogen bonds between N-CDs and PVA chains [97]. Moreover, an obvious increasing and shifting of C-O and C-O-C species from 1045.87 to $1095.56 \mathrm{~cm}^{-1}$ and 1016.56 to $979.05 \mathrm{~cm}^{-1}$, respectively were noticed, which indicated that both the oxygen-related surface states and topological defects were increased [98]. Additionally, the peak of $\mathrm{C}=\mathrm{O}$ stretching vibrations at $1641.26 \mathrm{~cm}^{-1}$ of $\mathrm{N}-\mathrm{CD}$ s shifted to 1646.84 , suggesting the formation of hydrogen bonding between the carboxyl groups of N-CDs surface and the hydroxyl groups of PVA [94]. All the changes in the peak positions and shapes confirmed the sufficient interaction between PVA and N-CDs. 

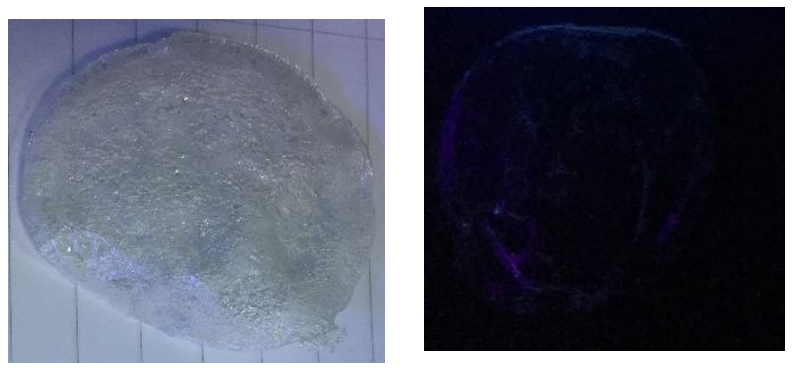

(a)
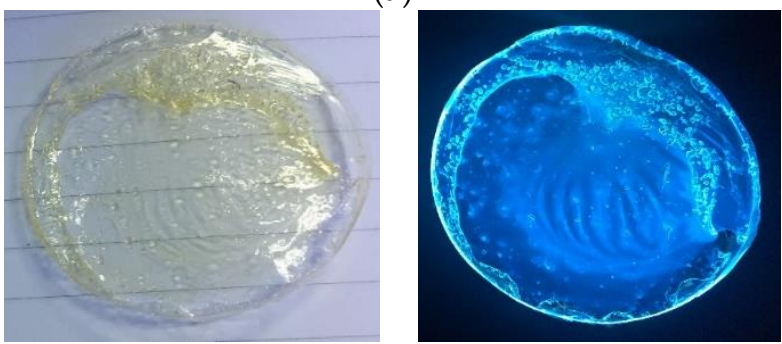

(b)

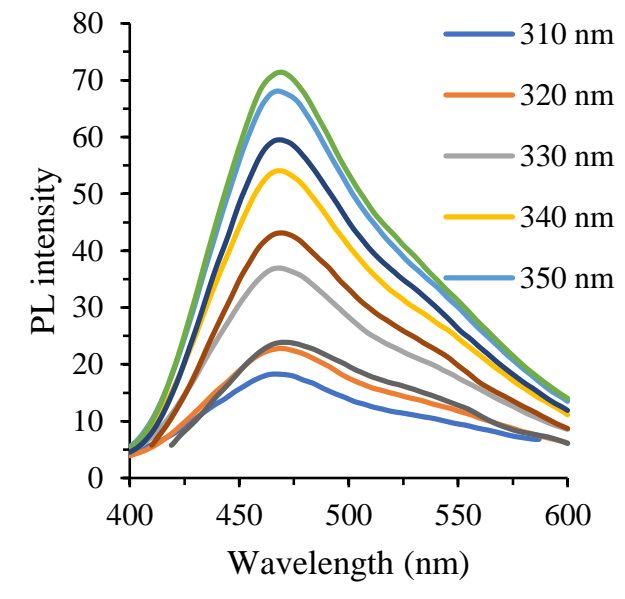

(c)

Figure 7. Photographs of poly (vinyl alcohol (PVA) film (a) before and (b) after encapsulating with $\mathrm{N}-\mathrm{CDs}$ under ambient light (up) and UV light (down) and (c) PL spectra of PVA/N-CDs film at different excitation wavelengths (310-390 nm).

The PL QY of the developed PVA/N-CDs film was calculated (Table S6) based on a comparative study and found to be $47 \%$, which was higher than that of the N-CDs solution. The PL enhancement might be due to the strong hydrogen bonding formation, which provides more efficient radiative recombination of the electrons/hole $(\mathrm{e}-\mathrm{h})$ pairs [96]. Furthermore, the photostability of the PVA/N-CDs film was found to be stable and no significant PL reduction was noticed even after $72 \mathrm{~h}$ of continuous irradiation to UV-excitation source (Figure S9). The PL efficiency enhancement and photostability feature of the developed PVA/N-CDs film confirms the potential of applying these composite films for a wide range of fields including solid-state lighting systems.

\section{Conclusions}

It can be concluded that highly luminescence, eco-friendly and water-soluble N-CDs have been successfully synthesized from CMC with the incorporation of LPEI as surface passivation agent/N-doping source through a one-step HTC route. By investigating the effects of reaction temperature, time and LPEI dosage on the optical properties of N-CDs, the optimal synthesis conditions were $260{ }^{\circ} \mathrm{C}$ reaction temperature, $2-\mathrm{h}$ duration and $1 \%$ of LPEI dosage. Under these optimal conditions, high PL QY of up to $44 \%$ was obtained, which was six times higher than undoped CDs under similar conditions. A bright greenish colour with excitation-dependent/independent emission was observed from the obtained N-CDs solution. More impressively, with the reduced concentration of the obtained N-CDs, PL emission enhancement and blue-shift in emission maxima were noticed. The highly photostable emission nature of N-CDs was explored for multiple applications. The as-made N-CDs could be significantly quenched by $\mathrm{Cu}^{2+}$ and a good relationship existed between the PL quenching ratio and the concentration of $\mathrm{Cu}^{2+}$, with LOD of $0.93 \mu \mathrm{M}$. Based on the vast information, coordination complexes could be formed between $\mathrm{Cu}^{2+}$ and nitrogen-containing species around N-CDs, leading to electron transfer and PL quenching. A solid-state composite film of PVA/N-CDs was developed and found to be highly transparent, stable and displayed only excitation independent emission behaviour. The PL QY of the PVA/N-CDs film was calculated to be $47 \%$, which was higher than that of N-CDs solution. This PL enhancement could be assigned to the radiative recombination of the $\mathrm{e}-\mathrm{h}$ pairs resulting from the strong hydrogen bonding formation. It is believed 
that the development of N-CDs composite film would have many potentials in fields of chemistry and biology in the near future.

Supplementary Materials: The following are available online at http://www.mdpi.com/2079-4991/9/10/1500/s1, Figure S1: Fundamental understanding of the N-CDs formation pathway, Figure S2: PL intensity as a function of (a) illumination time irradiated with UV light $(365 \mathrm{~nm})$ and (b) $\mathrm{NaCl}$ concentration, (c) $\mathrm{KCl}$ concentration and (d) temperatures, Figure S3: (a) Digital images showing N-CDs in ambient light and N-CDs and water under UV-lamp after six months at room temperature and (b) effect of storage time on the fluorescence intensity of the $\mathrm{N}-\mathrm{CDs}\left(0-6\right.$ months) at $25^{\circ} \mathrm{C}$, Figure S4: The effect of (a) sensing time and (b) pH value on the relative fluorescence quenching of $\mathrm{N}-\mathrm{CD}$ s before and after addition of $50 \mu \mathrm{M}$ of copper ions, Figure S5: DLS size distribution of $\mathrm{N}-\mathrm{CDs}$ after the addition of $700 \mu \mathrm{M}$ Cu (II), Figure S6: Zeta potential of N-CDs after the addition of $700 \mu \mathrm{M}$ $\mathrm{Cu}$ (II), Figure S7: PL spectra of N-CDs solution and N-CDs-PVA film showing (a) excitation and (b) emission maxima, Figure S8: FTIR spectra of the as-synthesized N-CDs and PVA/N-CDs film, Figure S9: Photostability of N-CDs-PVA composite film, Table S1: A summary of different starting materials used for synthesis of CDs, Table S2: Optimization of LPEI concentration for the production of N-CDs, Table S3: Optimization of synthesis conditions for the production of N-CDs, Table S4: Elemental compositions of the undoped and N-CDs, Table S5: Quantum yield calculation of PVA/N-CDs film.

Author Contributions: Z.Z.A. and M.A.I. conceptualization the overall idea of this research; S.R., S.S., M.A.M., N.A.I. and M.Y.P. contributed reagents/materials/analysis tools; M.A.I. wrote the paper; Z.Z.A. and M.A.I. review and editing the paper.

Funding: This research was funded by UPM grant number GP-IPS/2017/9556800.

Acknowledgments: I would like to express my sincere appreciation and deepest gratitude to my friend, Shahad Hadi, Almustansiriah University Department of Translation, for her hospitality and great arrangement to analyze the data and proofread the manuscript.

Conflicts of Interest: The authors declare no conflict of interest.

\section{References}

1. Sun, Y.-P.; Zhou, B.; Lin, Y.; Wang, W.; Fernando, K.A.S.; Pathak, P.; Meziani, M.J.; Harruff, B.A.; Wang, X.; Wang, H.; et al. Quantum-sized carbon dots for bright and colorful photoluminescence. J. Am. Chem. Soc. 2006, 128, 7756-7757. [CrossRef] [PubMed]

2. Liu, H.; Zhao, X.; Wang, F.; Wang, Y.; Guo, L.; Mei, J.; Tian, C.; Yang, X.; Zhao, D. High-Efficient Excitation-Independent Blue Luminescent Carbon Dots. Nanoscale Res. Lett. 2017, 12, 1-6. [CrossRef] [PubMed]

3. Ren, G.; Zhang, Q.; Li, S.; Fu, S.; Chai, F.; Wang, C.; Qu, F. One pot synthesis of highly fluorescent N doped $\mathrm{C}$-dots and used as fluorescent probe detection for $\mathrm{Hg}^{2+}$ and $\mathrm{Ag}^{+}$in aqueous solution. Sens. Actuators $B$ Chem. 2017, 243, 244-253. [CrossRef]

4. Sun, X.; Lei, Y. Fluorescent carbon dots and their sensing applications. Trends Anal. Chem. 2017, 89, 163-180. [CrossRef]

5. Li, L.; Dong, T. Photoluminescence Tuning in Carbon Dots: Surface Passivation or/and Functionalization, Heteroatom Doping. J. Mater. Chem. C 2018, 6, 7944-7970. [CrossRef]

6. Meiling, T.T. Development of a Reliable and Environmentally Friendly Synthesis for Fluorescence Carbon Nanodots; University of Potsdam: Potsdam, Germany, 2017.

7. Ortega-Liebana, M.C.; Chung, N.X.; Limpens, R.; Gomez, L.; Hueso, J.L.; Santamaria, J.; Gregorkiewicz, T. Uniform luminescent carbon nanodots prepared by rapid pyrolysis of organic precursors confined within nanoporous templating structures. Carbon N. Y. 2017, 117, 437-446. [CrossRef]

8. Xu, X.; Ray, R.; Gu, Y.; Ploehn, H.J.; Gearheart, L.; Raker, K.; Scrivens, W.A. Electrophoretic Analysis and Purification of Fluorescent Single-Walled Carbon Nanotube Fragments. J. Am. Chem. Soc. 2004, 126, 12736-12737. [CrossRef]

9. Li, H.; He, X.; Kang, Z.; Huang, H.; Liu, Y.; Liu, J.; Lian, S.; Tsang, C.H.; Yang, X.; Lee, S.T. Water-Soluble Fluorescent Carbon Quantum Dots and Photocatalyst Design. Angew. Chem. Int. Ed. 2010, 49, 4430-4434. [CrossRef]

10. Purbia, R.; Paria, S. A simple turn on fluorescent sensor for the selective detection of thiamine using coconut water derived luminescent carbon dots. Biosens. Bioelectron. 2016, 79, 467-475. [CrossRef] 
11. Sahu, S.; Behera, B.; Maiti, T.K.; Mohapatra, S. Simple one-step synthesis of highly luminescent carbon dots from orange juice: Application as excellent bio-imaging agents. Chem. Commun. 2012, 48, 8835-8837. [CrossRef]

12. Liu, H.; Ye, T.; Mao, C. Fluorescent carbon nanoparticles derived from candle soot. Angew. Chem. 2007, 46, 6473-6475. [CrossRef] [PubMed]

13. Qiao, Z.A.; Wang, Y.; Gao, Y.; Li, H.; Dai, T.; Liu, Y.; Huo, Q. Commercially activated carbon as the source for producing multicolor photoluminescent carbon dots by chemical oxidation. Chem. Commun. 2010, 46, 8812-8814. [CrossRef] [PubMed]

14. Li, H.; He, X.; Liu, Y.; Kang, Z. One-step ultrasonic synthesis of water-soluble carbon nanoparticles with excellent photoluminescent properties. Carbon N. Y. 2010, 49, 605-609. [CrossRef]

15. Mohapatra, S.; Sahu, S.; Sinha, N.; Bhutia, S.K. Synthesis of a carbon-dot-based photoluminescent probe for selective and ultrasensitive detection of $\mathrm{Hg}^{2+}$ in water and living cells. Analyst 2015, 140, 1221-1228. [CrossRef]

16. Hu, L.; Sun, Y.; Li, S.; Wang, X.; Hu, K.; Wang, L.; Liang, X.J.; Wu, Y. Multifunctional carbon dots with high quantum yield for imaging and gene delivery. Carbon N. Y. 2013, 67, 508-513. [CrossRef]

17. Kavitha, T.; Kumar, S. Turning date palm fronds into biocompatible mesoporous fluorescent carbon dots. Sci. Rep. 2018, 8, 1-10. [CrossRef]

18. Shen, P.; Gao, J.; Cong, J.; Liu, Z.; Li, C.; Yao, J. Synthesis of Cellulose-Based Carbon Dots for Bioimaging. Chem. Sel. 2016, 1, 1314-1317. [CrossRef]

19. Dou, Q.; Fang, X.; Jiang, S.; Chee, P.L.; Lee, T.C.; Loh, X.J. Multi-functional fluorescent carbon dots with antibacterial and gene delivery properties. RSC Adv. 2015, 5, 46817-46822. [CrossRef]

20. Wu, P.; Li, W.; Wu, Q.; Liu, Y.; Liu, S. Hydrothermal synthesis of nitrogen-doped carbon quantum dots from microcrystalline cellulose for the detection of Fe 3+ ions in an acidic environment. RSC Adv. 2017, 7, 44144-44153. [CrossRef]

21. Barati, A.; Shamsipur, M.; Arkan, E.; Hosseinzadeh, L.; Abdollahi, H. Synthesis of biocompatible and highly photoluminescent nitrogen doped carbon dots from lime: Analytical applications and optimization using response surface methodology. Mater. Sci. Eng. C 2015, 47, 325-332. [CrossRef]

22. D'Souza, S.L.; Deshmukh, B.; Bhamore, J.R.; Rawat, K.A.; Lenka, N.; Kailasa, S.K. Synthesis of fluorescent nitrogen-doped carbon dots from dried shrimps for cell imaging and boldine drug delivery system. RSC Adv. 2016, 6, 12169-12179. [CrossRef]

23. Essner, J.B.; Laber, C.H.; Ravula, S.; Polo-Parada, L.; Baker, G.A. Pee-dots: Biocompatible fluorescent carbon dots derived from the upcycling of urine. Green Chem. 2016, 18, 243-250. [CrossRef]

24. Huang, H.; Xu, Y.; Tang, C.-J.; Chen, J.-R.; Wang, A.-J.; Feng, J.-J. Facile and green synthesis of photoluminescent carbon nanoparticles for cellular imaging. New J. Chem. 2014, 38, 784. [CrossRef]

25. Liang, Q.; Ma, W.; Shi, Y.; Li, Z.; Yang, X. Easy synthesis of highly fluorescent carbon quantum dots from gelatin and their luminescent properties and applications. Carbon N. Y. 2013, 60, 421-428. [CrossRef]

26. Prasannan, A.; Imae, T. One-pot synthesis of fluorescent carbon dots from orange waste peels. Ind. Eng. Chem. Res. 2013, 52, 15673-15678. [CrossRef]

27. Dai, H.; Shi, Y.; Wang, Y.; Sun, Y.; Hu, J.; Ni, P.; Li, Z. A carbon dot based biosensor for melamine detection by fluorescence resonance energy transfer. Sens. Actuators B Chem. 2014, 202, 201-208. [CrossRef]

28. Wang, S.; Chen, Z.; Cole, I.; Li, Q. Structural evolution of graphene quantum dots during thermal decomposition of citric acid and the corresponding photoluminescence. Carbon N. Y. 2014, 82, 304-313. [CrossRef]

29. Wang, R.; Wang, X.; Sun, Y. One-step synthesis of self-doped carbon dots with highly photoluminescence as multifunctional biosensors for detection of iron ions and pH. Sens. Actuators B. Chem. 2017, 241, 73-79. [CrossRef]

30. Wu, Q.; Li, W.; Tan, J.; Wu, Y.; Liu, S. Hydrothermal carbonization of carboxymethylcellulose: One-pot preparation of conductive carbon microspheres and water-soluble fluorescent carbon nanodots. Chem. Eng. J. 2015, 266, 112-120. [CrossRef]

31. Alam, A.-M.; Park, B.-Y.; Ghouri, Z.K.; Park, M.; Kim, H.-Y. Synthesis of carbon quantum dots from cabbage with down- and up-conversion photoluminescence properties: Excellent imaging agent for biomedical applications. Green Chem. 2015, 17, 3791-3797. [CrossRef] 
32. De, B.; Karak, N. A green and facile approach for the synthesis of water soluble fluorescent carbon dots from banana juice. RSC Adv. 2013, 3, 8286-8290. [CrossRef]

33. Han, S.; Zhang, H.; Zhang, J.; Xie, Y.; Liu, L.; Wang, H.; Li, X.; Liu, W.; Tang, Y. Fabrication, gradient extraction and surface polarity-dependent photoluminescence of cow milk-derived carbon dots. RSC Adv. 2014, 4, 58084-58089. [CrossRef]

34. Jaiswal, A.; Ghosh, S.S.; Chattopadhyay, A. One step synthesis of C-dots by microwave mediated caramelization of poly(ethylene glycol). Chem. Commun. 2012, 48, 407-409. [CrossRef] [PubMed]

35. Lu, W.; Qin, X.; Liu, S.; Chang, G.; Zhang, Y.; Luo, Y.; Asiri, A.M.; Al-Youbi, A.O.; Sun, X. Economical, green synthesis of fluorescent carbon nanoparticles and their use as probes for sensitive and selective detection of mercury(II) ions. Anal. Chem. 2012, 84, 5351-5357. [CrossRef] [PubMed]

36. VMehta, N.; Jha, S.; Basu, H.; Singhal, R.K.; Kailasa, S.K. One-step hydrothermal approach to fabricate carbon dots from apple juice for imaging of mycobacterium and fungal cells. Sens. Actuators B Chem. 2015, 213, 434-443.

37. Mehta, V.N.; Jha, S.; Kailasa, S.K. One-pot green synthesis of carbon dots by using Saccharum officinarum juice for fluorescent imaging of bacteria (Escherichia coli) and yeast (Saccharomyces cerevisiae) cells. Mater. Sci. Eng. C 2014, 38, 20-27. [CrossRef] [PubMed]

38. Qin, X.; Lu, W.; Asiri, A.M.; Al-Youbi, A.O.; Sun, X. Microwave-assisted rapid green synthesis of photoluminescent carbon nanodots from flour and their applications for sensitive and selective detection of mercury(II) ions. Sens. Actuators B Chem. 2013, 184, 156-162. [CrossRef]

39. Qu, S.; Wang, X.; Lu, Q.; Liu, X.; Wang, L. A biocompatible fluorescent ink based on water-soluble luminescent carbon nanodots. Angew. Chem. Int. Ed. 2012, 51, 12215-12218. [CrossRef]

40. Shi, L.; Li, X.; Li, Y.; Wen, X.; Li, J.; Choi, M.M.; Dong, C.; Shuang, S. Naked oats-derived dual-emission carbon nanodots for ratiometric sensing and cellular imaging. Sens. Actuators B Chem. 2015, 210, 533-541. [CrossRef]

41. Tan, M.; Zhang, L.; Tang, R.; Song, X.; Li, Y.; Wu, H.; Wang, Y.; Lv, G.; Liu, W.; Ma, X. Enhanced photoluminescence and characterization of multicolor carbon dots using plant soot as a carbon source. Talanta 2013, 115, 950-956. [CrossRef]

42. Wang, B.; Wang, Y.; Wu, H.; Song, X.; Guo, X.; Zhang, D.; Ma, X.; Tan, M. A mitochondria-targeted fluorescent probe based on TPP-conjugated carbon dots for both one- and two-photon fluorescence cell imaging. RSC Adv. 2014, 4, 49960-49963. [CrossRef]

43. Wang, D.; Wang, X.; Guo, Y.; Liu, W.; Qin, W. Luminescent properties of milk carbon dots and their sulphur and nitrogen doped analogues. RSC Adv. 2014, 4, 51658-51665. [CrossRef]

44. Wang, Q.; Liu, X.; Zhang, L.; Lv, Y. Microwave-assisted synthesis of carbon nanodots through an eggshell membrane and their fluorescent application. Analyst 2012, 137, 5392-5397. [CrossRef] [PubMed]

45. KWu, H.; Fong, J.F.Y.; Luk, J.Z.; Gentle, I.R.; Wang, D.W. Fabrication, gradient extraction and surface polarity-dependent photoluminescence of cow milk-derived carbon dots $\mathrm{Co}(\mathrm{OH})_{2}$ Microplates. Cryst. Growth Des. 2016, 16, 8-11.

46. Xue, M.; Zhan, Z.; Zou, M.; Zhang, L.; Zhao, S. Green synthesis of stable and biocompatible fluorescent carbon dots from peanut shells for multicolor living cell imaging. New J. Chem. 2016, 40, 1698-1703. [CrossRef]

47. Yang, X.; Zhuo, Y.; Zhu, S.; Luo, Y.; Feng, Y.; Dou, Y. Novel and green synthesis of high-fluorescent carbon dots originated from honey for sensing and imaging. Biosens. Bioelectron. 2014, 60, 292-298. [CrossRef]

48. Kumar, P.; Kim, K.-H.; Bansal, V.; Lazarides, T.; Kumar, N. Progress in the sensing techniques for heavy metal ions using nanomaterials. J. Ind. Eng. Chem. 2017, 54, 30-43. [CrossRef]

49. Gumpu, M.B.; Sethuraman, S.; Krishnan, U.M.; Rayappan, J.B.B. A review on detection of heavy metal ions in water - An electrochemical approach. Sens. Actuators B Chem. 2015, 213, 515-533. [CrossRef]

50. Salinas-Castillo, A.; Ariza-Avidad, M.; Pritz, C.; Camprubí-Robles, M.; Fernández, B.; Ruedas-Rama, M.J.; Megia-Fernández, A.; Lapresta-Fernández, A.; Santoyo-Gonzalez, F.; Schrott-Fischer, A.; et al. Carbon dots for copper detection with down and upconversion fluorescent properties as excitation sources. Chem. Commun. 2013, 49, 1103. [CrossRef]

51. Lakowicz, J.R. Principles of Fluorescence Spectroscopy, 3rd ed.; Springer: Baltimore, MD, USA, 2006.

52. Zhu, H.; Wang, X.; Li, Y.; Wang, Z.; Yang, F.; Yang, X. Microwave synthesis of fluorescent carbon nanoparticles with electrochemiluminescence properties. Chem. Commun. 2009, 34, 5118-5120. [CrossRef] 
53. Sachdev, A.; Matai, I.; Gopinath, P. Implications of surface passivation on physicochemical and bioimaging properties of carbon dots. RSC Adv. 2014, 4, 20915-20921. [CrossRef]

54. Kumar, P.; Barrett, D.M.; Delwiche, M.J.; Stroeve, P. Methods for pretreatment of lignocellulosic biomass for efficient hydrolysis and biofuel production. Ind. Eng. Chem. Res. 2009, 48, 3713-3729. [CrossRef]

55. Issa, M.A.; Abidin, Z.Z.; Sobri, S.; Abdul-Rashid, S.; Mahdi, M.A.; Ibrahim, N.A.; Pudza, M.Y. Fabrication, characterization and response surface method optimization for quantum efficiency of fluorescent nitrogen-doped carbon dots from carboxymethylcellulose derived from empty fruit bunch of oil palms. Chin. J. Chem. Eng. 2019. [CrossRef]

56. Da Silva Souza, D.R.; Caminhas, L.D.; de Mesquita, J.P.; Pereira, F.V. Luminescent carbon dots obtained from cellulose. Mater. Chem. Phys. 2018, 203, 148-155. [CrossRef]

57. Zhou, J.; Zhou, H.; Tang, J.; Deng, S.; Yan, F.; Li, W.; Qu, M. Carbon dots doped with heteroatoms for fluorescent bioimaging: A review. Microchim. Acta 2017, 184, 343-368. [CrossRef]

58. Sachdev, A.; Gopinath, P. Green synthesis of multifunctional carbon dots from coriander leaves and their potential application as antioxidants, sensors and bioimaging agents. Analyst 2015, 140, 4260-4269. [CrossRef]

59. Liu, Y.; Zhou, Q.; Li, J.; Lei, M.; Yan, X. Selective and sensitive chemosensor for lead ions using fluorescent carbon dots prepared from chocolate by one-step hydrothermal method. Sens. Actuators B Chem. 2016, 237, 597-604. [CrossRef]

60. Alas, M.O.; Genc, R. An investigation into the role of macromolecules of different polarity as passivating agent on the physical, chemical and structural properties of fluorescent carbon nanodots An investigation into the role of macromolecules of different polarity as passi. J. Nanopart. Res. 2017, 19, 185. [CrossRef]

61. Arul, V.; Sethuraman, M.G. Facile green synthesis of fluorescent N-doped carbon dots from Actinidia deliciosa and their catalytic activity and cytotoxicity applications. Opt. Mater. 2018, 78, 181-190. [CrossRef]

62. Liao, J.; Cheng, Z.; Zhou, L. Nitrogen-Doping Enhanced Fluorescent Carbon Dots: Green Synthesis and Their Applications for Bioimaging and Label-Free Detection of $\mathrm{Au}^{3+}$ Ions. ACS Sustain. Chem. Eng. 2016, 4, 3053-3061. [CrossRef]

63. Liu, J.; Liu, X.; Luo, H.; Gao, Y. One-step preparation of nitrogen-doped and surface-passivated carbon quantum dots with high quantum yield and excellent optical properties. RSC Adv. 2014, 4, 7648. [CrossRef]

64. Ding, H.; Wei, J.S.; Zhang, P.; Zhou, Z.Y.; Gao, Q.Y.; Xiong, H.M. Solvent-Controlled Synthesis of Highly Luminescent Carbon Dots with a Wide Color Gamut and Narrowed Emission Peak Widths. Small 2018, 14, 1-10. [CrossRef]

65. Zhang, Y.; He, Y.H.; Cui, P.P.; Feng, X.T.; Chen, L.; Yang, Y.Z.; Liu, X.G. Water-soluble, nitrogen-doped fluorescent carbon dots for highly sensitive and selective detection of $\mathrm{Hg}^{2+}$ in aqueous solution. RSC Adv. 2015, 5, 40393-40401. [CrossRef]

66. Wang, Y.; Zhu, Y.; Yu, S.; Jiang, C. Fluorescent carbon dots: Rational synthesis, tunable optical properties and analytical applications. RSC Adv. 2017, 7, 40973-40989. [CrossRef]

67. Arul, V.; Sethuraman, M.G. Hydrothermally Green Synthesized Nitrogen-Doped Carbon Dots from Phyllanthus emblica and Their Catalytic Ability in the Detoxification of Textile Effluents. ACS Omega 2019, 4, 3449-3457. [CrossRef]

68. Minh, L.; Phan, T.; Hoon, S.; Phan, T.; Yeol, K.; Ha, S. Synthesis of fluorescent silicon quantum dots for ultra-rapid and selective sensing of $\mathrm{Cr}(\mathrm{VI})$ ion and biomonitoring of cancer cells. Mater. Sci. Eng. C J. 2018, 93, 429-436.

69. Gao, X.; Du, C.; Zhuang, Z.; Chen, W. Carbon quantum dot-based nanoprobes for metal ion detection. J. Mater. Chem. C 2016, 4, 6927-6945. [CrossRef]

70. Yang, Z.; Xu, M.; Liu, Y.; He, F.; Gao, F.; Su, Y.; Wei, H.; Zhang, Y. Nitrogen-doped, carbon-rich, highly photoluminescent carbon dots from ammonium citrate. Nanoscale 2014, 6, 1890-1895. [CrossRef]

71. Kumawat, M.K.; Thakur, M.; Gurung, R.B.; Srivastava, R. Graphene Quantum Dots for Cell Proliferation, Nucleus Imaging, and Photoluminescent Sensing Applications. Sci. Rep. 2017, 7, 1-16. [CrossRef]

72. Liang, Z.; Zeng, L.; Cao, X.; Wang, Q.; Wang, X.; Sun, R. Sustainable carbon quantum dots from forestry and agricultural biomass with amplified photoluminescence by simple $\mathrm{NH}_{4} \mathrm{OH}$ passivation. J. Mater. Chem. C 2014, 2, 9760-9766. [CrossRef]

73. Chandra, S.; Patra, P.; Pathan, S.H.; Roy, S.; Mitra, S.; Layek, A.; Bhar, R.; Pramanik, P.; Goswami, A. Luminescent S-doped carbon dots: An emergent architecture for multimodal applications. J. Mater. Chem. B 2013, 1, 2375-2382. [CrossRef] 
74. Patir, K.; Gogoi, S.K. Nitrogen-doped carbon dots as fluorescence ON-OFF-ON sensor for parallel detection of copper(II) and mercury(II) ions in solutions as well as in filter paper-based microfluidic devicet. Nanoscale Adv. 2018, 1, 592-601. [CrossRef]

75. Stafiej, A.; Pyrzynska, K. Adsorption of heavy metal ions with carbon nanotubes. Seperation Purif. Technol. 2007, 58, 49-52. [CrossRef]

76. Zhuo, K.; Sun, D.; Xu, P.; Wang, C.; Cao, Y.; Chen, Y.; Liu, J. Green synthesis of sulfur- and nitrogen-co-doped carbon dots using ionic liquid as a precursor and their application in $\mathrm{Hg}^{2+}$ detection. J. Lumin. 2017, 187, 227-234. [CrossRef]

77. Dong, Y.; Wang, R.; Li, G.; Chen, C.; Chi, Y.; Chen, G. Polyamine-functionalized carbon quantum dots as fluorescent probes for selective and sensitive detection of copper ions. Anal. Chem. 2012, 84, 6220-6224. [CrossRef]

78. Wu, X.; Wu, L.; Cao, X.; Li, Y.; Liu, A.; Liu, S. Nitrogen-doped carbon quantum dots for fluorescence detection of $\mathrm{Cu}^{2+}$ and electrochemical monitoring of bisphenol, A. RSC Adv. 2018, 8, 20000-20006. [CrossRef]

79. Kong, D.; Yan, F.; Shi, D.; Ye, Q.; Han, Z.; Chen, L.; Wang, L. Carbon dots: Synthetic methods and applications as fluorescent probes for the detection of metal ions, inorganic anions and organic molecules. J. Iran. Chem. Soc. 2015, 12, 1841-1857. [CrossRef]

80. Nurerk, P.; Kanatharana, P.; Bunkoed, O. A selective determination of copper ions in water samples based on the fluorescence quenching of thiol-capped CdTe quantum dots. Luminescence 2016, 31, 515-522. [CrossRef]

81. Yang, G.; Wan, X.; Liu, Y.; Li, R.; Su, Y.; Zeng, X.; Tang, J. Luminescent poly (vinyl alcohol)/carbon quantum dots composites with tunable water-induced shape memory behavior in different $\mathrm{pH}$ and temperature environments. ACS Appl. Mater. Interfaces 2016, 8, 34744-34754. [CrossRef]

82. Wang, Y.; Zhao, Y.; Zhang, F.; Chen, L.; Yang, O.; Liu, X. Fluorescent polyvinyl alcohol films based on nitrogen and sulfur co-doped carbon dots towards white light-emitting devices. New J. Chem. 2016, 40, 8710-8716. [CrossRef]

83. Hu, M.; Gu, X.; Hu, Y.; Deng, Y.; Wang, C. PVA/Carbon Dot Nanocomposite Hydrogels for Simple Introduction of Ag Nanoparticles with Enhanced Antibacterial Activity. Macromol. Mater. Eng. 2016, 301, 1352-1362. [CrossRef]

84. Online, V.A.; Taspika, M.; Permatasari, F.A.; Nuryadin, B.W.; Mayangsari, T.R.; Iskandar, F. Simultaneous ultraviolet and first near-infrared window absorption of luminescent carbon dots/PVA composite film. RSC Adv. 2019, 9, 7375-7381.

85. Bandi, R.; Devulapalli, N.P.; Dadigala, R.; Gangapuram, B.R.; Guttena, V. Facile Conversion of Toxic Cigarette Butts to N,S-Codoped Carbon Dots and Their Application in Fluorescent Film, Security Ink, Bioimaging, Sensing and Logic Gate Operation. ACS Omega 2018, 3, 13454-13466. [CrossRef]

86. Liu, Y.; Deng, M.; Zhu, T.; Tang, X.; Han, S.; Huang, W.; Shi, Y.; Liu, A. The synthesis of water-dispersible zinc doped AgInS2 quantum dots and their application in $\mathrm{Cu}^{2+}$ detection. J. Lumin. 2017, 192, 547-554. [CrossRef]

87. Aziz, S.B.; Hassan, A.Q.; Mohammed, S.J.; Karim, W.O.; Kadir, M.F.; Tajuddin, H.A.; Chan, N.N. Structural and Optical Characteristics of PVA: C-Dot Composites: Tuning the Absorption of Ultra Violet (UV) Region. Nanomaterials 2019, 9, 216. [CrossRef]

88. Singh, V.; Kumar, V.; Yadav, U.; Srivastava, R.K.; Singh, V.N.; Banerjee, A.; Chakraborty, S.; Shukla, A.K.; Misra, D.K.; Ahuja, R.; et al. Sensitive and selective detection of copper ions using low cost nitrogen doped carbon quantum dots as a fluorescent sensing plateform. ISSS J. Micro Smart Syst. 2017, 6, 109-117. [CrossRef]

89. Chan, Y.; Chen, J.; Liu, Q.; Wark, S.E.; Son, D.H.; Batteas, J.D. Ultrasensitive Copper (II) Detection Using Luminescence of CdSe Quantum Dots. Anal. Chem. 2010, 82, 3671-3678. [CrossRef]

90. Zhu, A.; Qu, Q.; Shao, X.; Kong, B.; Tian, Y. Carbon-Dot-Based Dual-Emission Nanohybrid Produces a Ratiometric Fluorescent Sensor for In Vivo Imaging of Cellular Copper Ions. Angew. Chem. Int. Ed. 2012, 51, 7185-7189. [CrossRef]

91. Wen, X.; Nadirah, A.; Romainor, B.; Fun, S.; Muk, S. Carbon dots production via pyrolysis of sago waste as potential probe for metal ions sensing. J. Anal. Appl. Pyrolysis 2014, 105, 157-165.

92. Liu, S.; Tian, J.; Wang, L.; Zhang, Y.; Qin, X.; Luo, Y.; Asiri, A.M.; Al-Youbi, A.O.; Sun, X. Hydrothermal treatment of grass: A low-cost, green route to nitrogen-doped, carbon-rich, photoluminescent polymer nanodots as an effective fluorescent sensing platform for label-free detection of $\mathrm{Cu}(\mathrm{II})$ ions. Adv. Mater. 2012, 24, 2037-2041. [CrossRef] 
93. Ma, X.; Dong, Y.; Sun, H.; Chen, N. Highly fluorescent carbon dots from peanut shells as potential probes for copper ion: The optimization and analysis of the synthetic process. Mater. Today Chem. 2017, 5, 1-10. [CrossRef]

94. Zong, J.; Yang, X.; Trinchi, A.; Hardin, S.; Cole, I.; Zhu, Y.; Li, C.; Muster, T.; Wei, G. Carbon dots as fluorescent probes for 'off-on' detection of $\mathrm{Cu}^{2+}$ and L-cysteine in aqueous solution. Biosens. Bioelectron. 2014, 51, 330-335. [CrossRef]

95. Salinas-castillo, A.; Morales, D.P.; Lapresta-fernández, A.; Ariza-avidad, M.; Castillo, E.; Martínez-olmos, A. Evaluation of a reconfigurable portable instrument for copper determination based on luminescent carbon dots. Anal. Bioanal. Chem. 2016, 408, 3013-3020. [CrossRef]

96. Ganiga, M.; Cyriac, J. Understanding the Photoluminescence Mechanism of Nitrogen-Doped Carbon Dots by Selective Interaction with Copper Ions. ChemPhysChem 2016, 17, 2315-2321. [CrossRef]

97. Zheng, X.; Liu, W.; Gai, Q.; Tian, Z.; Ren, S. A Carbon-Dot-Based Fluorescent Probe for the Sensitive and Selective Detection of Copper(II) Ions. ChemistrySelect 2019, 4, 2392-2397. [CrossRef]

98. Hao, Y.; Gan, Z.; Xu, J.; Wu, X.; Chu, P.K. Applied Surface Science Poly (ethylene glycol)/carbon quantum dot composite solid films exhibiting intense and tunable blue-Red emission. Appl. Surf. Sci. 2014, 311, 490-497. [CrossRef]

(C) 2019 by the authors. Licensee MDPI, Basel, Switzerland. This article is an open access article distributed under the terms and conditions of the Creative Commons Attribution (CC BY) license (http://creativecommons.org/licenses/by/4.0/). 